\title{
Optogenetically-Induced Population Discharge Threshold as a Sensitive Measure of Network Excitability
}

\author{
D. D. C. Klorig, ${ }^{1,2}$ G. E. Alberto, ${ }^{1,2}$ T. Smith, ${ }^{1}$ and D. W. Godwin ${ }^{1,2,3}$
}

https://doi.org/10.1523/ENEURO.0229-18.2019

${ }^{1}$ Department of Neurobiology and Anatomy, ${ }^{2}$ Neuroscience Program, and ${ }^{3}$ Department of Physiology and Pharmacology, Wake Forest University, Winston-Salem, NC

\begin{abstract}
Network excitability is governed by synaptic efficacy, intrinsic excitability, and the circuitry in which these factors are expressed. The complex interplay between these factors determines how circuits function and, at the extreme, their susceptibility to seizure. We have developed a sensitive, quantitative estimate of network excitability in freely behaving mice using a novel optogenetic intensity-response procedure. Synchronous activation of deep sublayer CA1 pyramidal cells produces abnormal network-wide epileptiform population discharges (PDs) that are nearly indistinguishable from spontaneously-occurring interictal spikes (IISs). By systematically varying light intensity, and therefore the magnitude of the optogenetically-mediated current, we generated intensityresponse curves using the probability of $\mathrm{PD}$ as the dependent variable. Manipulations known to increase excitability, such as sub-convulsive doses $(20 \mathrm{mg} / \mathrm{kg}$ ) of the chemoconvulsant pentylenetetrazol (PTZ), produced a leftward shift in the curve compared to baseline. The anti-epileptic drug levetiracetam (LEV; $40 \mathrm{mk} / \mathrm{kg}$ ), in combination with PTZ, produced a rightward shift. Optogenetically-induced PD threshold (oPDT) baselines were stable over time, suggesting the metric is appropriate for within-subject experimental designs with multiple pharmacological manipulations.
\end{abstract}

Key words: epilepsy; excitability; intensity response; network; optogenetics; seizure

\section{Significance Statement}

Abnormal excitability is associated with a number of neurologic disorders, including epilepsy. Excitability can be measured in single cells in vitro, but it is difficult to extrapolate from these values to the functional impact on the associated network. Epileptiform population discharges (PDs) are network-wide events that represent a distinct transition from normal to abnormal functional modes. We developed a new method that uses light intensity-response curves to precisely determine the threshold for this transition as a surrogate measure of network excitability.

\section{Introduction}

Seizure thresholds are commonly used to determine excitability and seizure susceptibility in animal models of epilepsy and to assess the effectiveness of therapeutic

Received June 7, 2018; accepted September 27, 2019; First published October 16, 2019.

The authors declare no competing financial interests.

Author contributions: D.C.K. and G.E.A. designed research; D.C.K., G.E.A., and T.S. performed research; D.C.K. contributed unpublished reagents/anaIytic tools; D.C.K. analyzed data; D.C.K., G.E.A., and D.W.G. wrote the paper. intervention (Spiegel, 1937; Ziskind et al., 1946; Swinyard et al., 1952; Barton et al., 2001). However, seizures have lasting effects on the brain, including widespread changes in gene expression (Altar et al., 2004), reduced seizure thresholds, and increased seizure severity (Racine,

This work was supported by Department of Health and Human Services (HHS) National Institutes of Health (NIH) National Institute on Alcohol Abuse and Alcoholism Grants R01AA016852 and F31AA021322, the HHS NIH National Institute of Neurological Disorders and Stroke Grant R01NS105005 and T32NS073553, and the Tab Williams Family Fund. 
1972a). This complicates the interpretation of withinsubject experiments and limits the ability to make multiple measurements over time. Furthermore, excitability is dynamically modulated by ongoing brain activity and behavioral state, which introduces significant variability, limiting the precision of acute threshold measurements. Single pulse electrical stimulation, a technique used in humans undergoing intraoperative monitoring, provides a measure of network excitability without inducing seizure (Matsumoto et al., 2017). However, this method is limited by the uncertainty of the cells and pathways stimulated (Histed et al., 2009), and the ambiguity of amplitude based LFP measurements in relation to underlying activity (Hales and Pockett, 2014; Herreras, 2016). Excitability and seizure susceptibility can also be estimated by quantification of spontaneous seizures in models of epileptogenesis, but this approach is complicated by the unpredictable occurrence of seizures, requiring constant video-EEG monitoring, prolonged drug administration, and large numbers of animals (Löscher, 2011).

To obtain more precise and reliable measurements, we have developed a rigorous approach for quantifying instantaneous network excitability, without inducing seizures, using single pulse light intensity-response curves to determine population discharge (PD) thresholds. Optogenetically-induced PDs (oPDs) are all-or-none, networkwide events with waveforms and latencies similar to spontaneously-occurring interictal spikes (IISs). We show that induced oPDs occur with a higher likelihood with increasing light intensity. By delivering a range of light intensities with randomized presentation order and modeling oPD probability using logistic regression, we account for short-term fluctuations in excitability and derive a new metric, the 150 , defined as the intensity of light that produces an OPD with a probability of 0.5 . Using established pharmacologic modulators, we demonstrate that the 150 is sensitive to shifts in excitability. The oPD threshold (oPDT) can be monitored over long timescales with high temporal resolution to fully capture the dynamics of network excitability. Furthermore, because it does not involve the generation of after-discharges (ADs) or seizures, the oPDT can be used as a measure of excitability in a range of normal and pathologic conditions other than epilepsy.

Using the same preparation, we show that repetitive stimulation with light of a sufficient intensity produces a robust $A D$ and kindling with daily $A D s$ results in overt behavioral seizure. In the same animal, the optogenetic $A D$ threshold (OADT) and the oPDT are equivalent in terms

Acknowledgements: We thank Dorothy Dobbins, Allison Goldstein, Rasesh Joshi, Glen Marrs, and Hong Qu Shan for help with this project and useful comments on this manuscript. Portions of this work were previously reported in abstract form (Klorig et al., 2014, 2017).

Correspondence should be addressed to D. C. Klorig at dklorig@ wakehealth.edu or at neuroptics@gmail.com.

https://doi.org/10.1523/ENEURO.0229-18.2019

Copyright (C) 2019 Klorig et al.

This is an open-access article distributed under the terms of the Creative Commons Attribution 4.0 International license, which permits unrestricted use, distribution and reproduction in any medium provided that the original work is properly attributed. of light intensity. The oADT, however, requires an additional accumulating process involving multiple oPDs in a short period of time. Comparing the two metrics allows for separation of the contribution of instantaneous excitability, and robustness to seizure, or susceptibility, features that are inseparably intertwined in other measures of seizure threshold.

\section{Materials and Methods}

\section{Subjects}

Male Thy1-ChR2-YFP (founder line 18) transgenic mice (Arenkiel et al., 2007; Wang et al., 2007; stock \#007612, The Jackson Laboratory) were used for chronic optogenetic stimulation and recording $(n=35)$. Thy 1 line 18 mice express wild-type ChR2 fused to EYFP in area CA1, subiculum (Sub), and layer 5 of cortex (Arenkiel et al., 2007). In area $\mathrm{CA} 1$, expression is specific to excitatory pyramidal neurons and is concentrated in calbindin-negative cells in the deep pyramidal cell sublayer (Dobbins et al., 2018). These mice can be bred as homozygotes, ensuring consistent expression levels and patterns from animal to animal, a significant advantage for reproducibility. For this reason, they are used in a number of optogenetics studies (Ting and Feng, 2013). Not all animals were used for all experiments; exact numbers are reported throughout. All animal experiments were approved by the Institutional Animal Care and Use Committee (IACUC) of Wake Forest University in agreement with National Institutes of Health and United States Department of Agriculture guidelines.

\section{Chronic implant}

Details of the implantation surgery and chronic recording array are described in a previous publication (Klorig and Godwin, 2014). Briefly, Thy 1 mice (age two to nine months, mean $120 \pm 9$ d) were anesthetized with isoflurane and placed in a stereotaxic device. All surgical procedures were performed under red light to avoid sustained activation of ChR2. Metal ground screws were secured to the cranium bilaterally so that they were in contact with the subarachnoid space posterior to the transverse sinus. A total of 8 tungsten microwires were implanted in a satellite array in cortical, subcortical, and hippocampal locations: prefrontal cortex (PFC; AP: 5.58 $\mathrm{mm}, \mathrm{L}: 0.37 \mathrm{~mm}, \mathrm{DV}:-1.81 \mathrm{~mm}$, from the interaural plane), anterior medial thalamic nucleus (AMTh; AP: $2.86 \mathrm{~mm}$, L: $0.24 \mathrm{~mm}$, DV: $-3.62 \mathrm{~mm}$ ), dentate gyrus (DG; AP: 1.50 $\mathrm{mm}, \mathrm{L}: 1.39 \mathrm{~mm}$, DV: $-1.61 \mathrm{~mm})$, hippocampus (CA3; AP: $1.34 \mathrm{~mm}, \mathrm{~L}: 2.88 \mathrm{~mm}, \mathrm{DV}:-2.12 \mathrm{~mm}$ ), entorhinal cortex (Ent; AP: $0.19 \mathrm{~mm}$, L: $3.90 \mathrm{~mm}$, DV: $-2.73 \mathrm{~mm}$, angled $16^{\circ}$ posterior), Sub (AP: $0.88 \mathrm{~mm}$, L: $1.02 \mathrm{~mm}$, DV: $-1.43 \mathrm{~mm}$ ), and left CA1 (AP: $1.00 \mathrm{~mm}$, L: $-2.36 \mathrm{~mm}$, DV: $-1.20 \mathrm{~mm}$; Fig. 1A). A magnetic rotary fiber connector with an attached microwire (optrode) was placed in intermediate CA1 near Sub (CA1a; AP: 1.00 mm, L: 2.36 mm, DV: -1.20 $\mathrm{mm}$, from the interaural plane). The stimulation fiber was a multimodal fiber with a $200 \mu \mathrm{m}$ diameter core and a numerical aperture of 0.39 (FT200UMT, ThorLabs). The recording electrode extended $0.5 \mathrm{~mm}$ beyond the fiber tip. The optical fiber was situated $0.4 \mathrm{~mm}$ dorsal to the pyramidal cell layer and $0.3 \mathrm{~mm}$ dorsal to the basal den- 
A
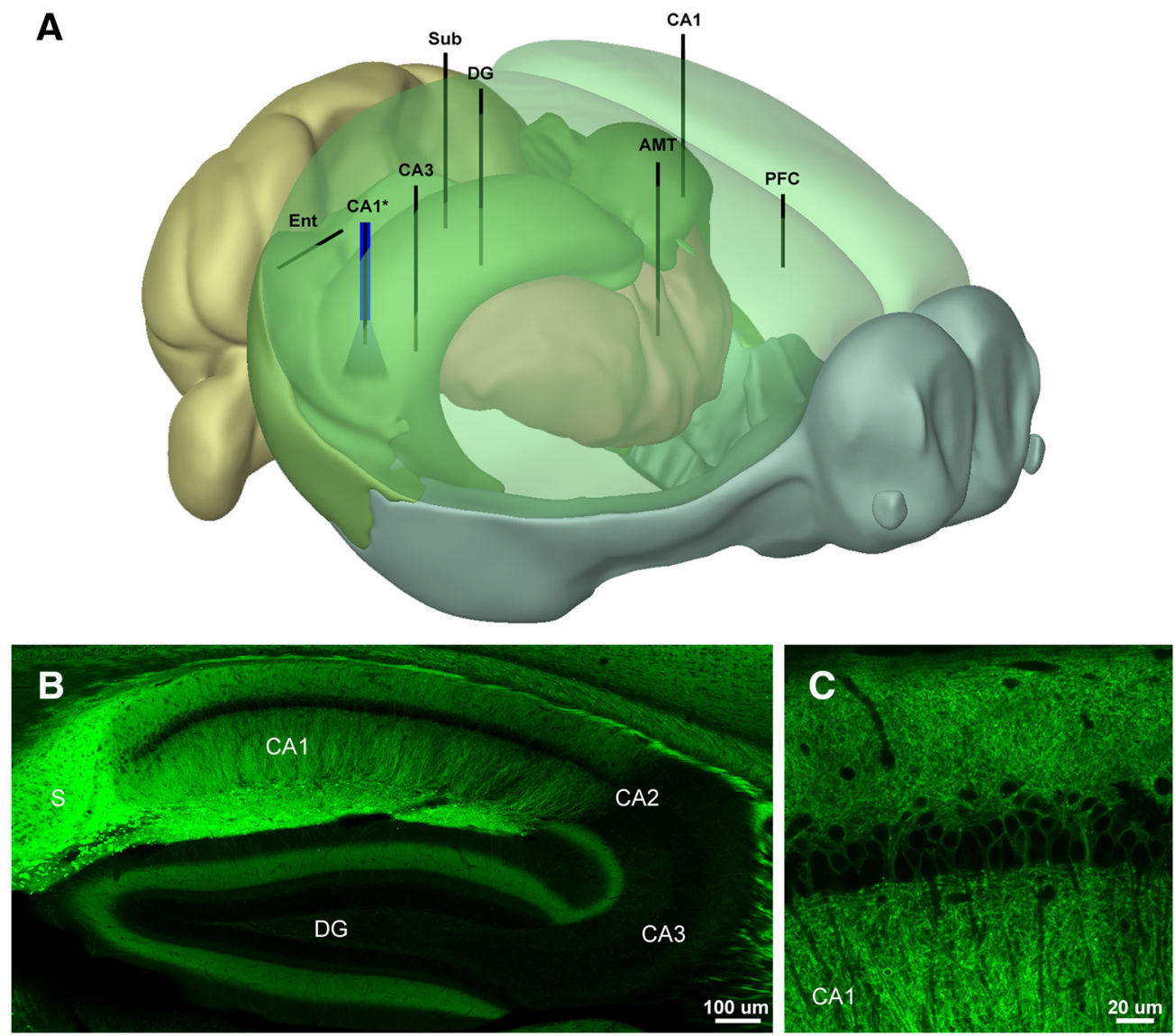

Figure 1. Electrode placement and expression patterns in the Thy1-ChR2 (line 18) mouse. A, Schematic showing the placement of the electrode array and optrode. $\boldsymbol{B}$, Distribution of ChR2-EYFP in the hippocampus of the Thy1 (line 18) mouse. Note high expression levels in CA1 and Sub; 10× tiled confocal image. C, ChR2-EYFP is expressed in deep pyramidal neurons in CA1 (Dobbins et al., 2018); $63 \times$ oil immersion confocal image. The 3D model was generated using Brain Explorer Software courtesy of the Allen Brain Institute (http://mouse.brain-map.org/static/brainexplorer).

drites. The optrode was configured to minimize the photovoltaic effect $(<0.02 \%$ LFP amplitude) by cutting the electrode at an angle so that the exposed metal surface was not directly illuminated by the implanted fiber (Cardin et al., 2010). Wild-type $(n=2)$ and postmortem control ( $n$ $=4$ ) recordings were used to confirm the absence of artifact. This setup allowed for high quality recordings, free of movement artifacts, even during behavioral seizures.

\section{Light stimulation and recordings}

Mice were allowed to recover one week before recordings. Wideband $(0.3-20 \mathrm{kHz}$, sampled at $40 \mathrm{kHz})$ depth recordings were made using the SciWorks recording system (DataWave Technologies), AM-3600 extracellular amplifiers (A-M Systems), and T8G100 headstage amplifiers (TBSI). Photostimulation was performed with a fibercoupled LED with peak emission at $470 \mathrm{~nm}$ (M470F3, ThorLabs). LED intensity was controlled using an LED driver with analog modulation (LEDD1B, ThorLabs). Analog output pulses were generated within SciWorks and used to control the LED driver. Light pulses were continually monitored with a silicon photodiode placed near the emitter. A custom op-amp based current-to-voltage con- verter circuit was used to linearize the photodiode output and the resulting signals were recorded along with the electrophysiology data. Two measures of light output are provided; the power $(\mathrm{mW})$ at the tip of the source fiber and an arbitrary linearized scale. Light power ranged from 0.43 to $4.15 \mathrm{~mW}$ at the fiber tip corresponding to an irradiance of $0.2-1.96 \mathrm{~mW} / \mathrm{mm}^{2}$ at the recording site estimated using the empirically derived model described in (Aravanis et al., 2007; Yizhar et al., 2011).

\section{Video and behavioral scoring}

Recording sessions were video recorded and an infrared LED synchronized to the stimulus onset was placed in view of the video camera for precise temporal alignment between the video and the recordings. Video was used for assessment of behavioral seizures using a modified Racine scale (Racine, 1972b; Pinel and Rovner, 1978). Latencies to seizure stage relative to the onset of the stimulus and durations were also recorded.

\section{Histologic verification of electrode placement}

On completion of recording experiments, mice were anesthetized with Euthasol (Virbac Animal Health), electrolytic lesions were performed at each electrode site (20 
$\mathrm{nA}, 10 \mathrm{~s}$ ), then animals were transcardially perfused with saline and $4 \%$ paraformaldehyde solution in PB. After removal and postfixing, brains were sectioned in $50-\mu \mathrm{m}$ slices using a vibratome. The slices were then mounted on slides and stained using cresyl violet (Nissl). Each slice was imaged using a light microscope and the stereotaxic coordinates of the implanted electrodes were recorded. Animals were excluded from further analysis if electrodes used in those analyses were located outside of the target areas $(n=5)$.

\section{Confocal microscopy}

ChR2-eYFP expression in Thy 1 mice was imaged in non-implanted animals. Confocal imaging was performed on a Zeiss LSM 710 confocal microscope with $10 \times, 20 \times$ air, and $60 \times$ water immersion objectives.

\section{Experimental design and statistical analysis}

Data analysis was performed using custom scripts written in MATLAB (MathWorks). The suite of stimulus presentation and analysis tools used to generate and calculate the oPDT is available on github (https://github. com/neuroptics/optoDR).

\section{oPD intensity-response curve}

Single square pulses (10 ms) of light were delivered at a range of intensities (20 levels, $0.43-4.15 \mathrm{~mW}$ at fiber tip, $0.2-1.96 \mathrm{~mW} / \mathrm{mm}^{2}$ at the recording site). Sixty repetitions of each intensity were presented in randomly ordered blocks with a 1- or 3-s interval between pulses. A timing pulse was used to precisely align responses to the onset of the LED. For the PD curves, time-locked evoked responses were extracted, the 2nd derivative calculated, and a sliding window $(10 \mathrm{~ms})$ was used to calculate root-mean-square (RMS) power via convolution. The max RMS within a specified time window was calculated, sorted by magnitude, and plotted for each channel over all stimulation levels. The channel with the sharpest transition between sub-PD and PD was chosen and the threshold set (typically contralateral CA1, but occasionally DG or CA3 were chosen). PD detection was verified visually. All subsequent analyses for a given animal were performed with the same channel and threshold. The ratio of PD events per level was calculated to generate a probability curve. This curve was fit by the Hodgkin and Huxley formulation of the Boltzmann distribution:

$$
f(x)=\frac{1}{1+e^{\left(\frac{a-x}{b}\right)}},
$$

where $a$ is the 150 , and $b$ is the slope (Hodgkin and Huxley, 1952), using nonlinear regression (least squares) in MATLAB. The 150 value for each session was then used for further comparisons.

\section{OADT and kindling procedure}

OADTs were determined by presenting optical stimulation trains at $6.67 \mathrm{~Hz}$ (10-s duration, 4-ms pulse, 150-ms interval, 66 pulses), then increasing the intensity (with a 2-min interval) until an AD was evoked (characterized by high amplitude, self-sustaining activity that persisted $>5 \mathrm{~s}$ after the stimulus ended). A modified optogenetic kindling procedure was used that allowed for estimation of OADTs, involving repeated daily light stimulation at increasing intensity until an AD was evoked (with intensities identical to that performed on the first day), similar to established procedures (Pinel et al., 1976; Bragin et al., 2002). ADs were defined as sustained high-amplitude spike and polyspike activity lasting at least $5 \mathrm{~s}$ following termination of the stimulus. OAD durations were measured from the start of the stimulus to the last spike of the oAD. Only one oAD was evoked per 24-h period. This procedure was repeated each day for $15 \mathrm{~d}$.

\section{Pharmacology}

All experiments used a within-subjects design. Treatments were compared to a pre-treatment baseline using repeated measures one-way ANOVA with Tukey's test for multiple comparisons. Saline controls were also performed and compared to pre-injection baselines.

\section{Statistics and measures of reliability}

Statistical testing was performed with MATLAB and Prism (GraphPad). All means are reported $\pm \mathrm{SD}$, with 95\% confidence intervals $(\mathrm{Cl})$ where appropriate. Datasets were tested for normality using the omnibus $\mathrm{K}^{2}$ test (D'Agostino et al., 1990). Comparisons were performed using repeated measures one-way ANOVA with Tukey's test for multiple comparisons, paired $t$ tests, Fischer's exact test, or Wilcoxon matched pairs test where appropriate. Correlation coefficients were calculated using Pearson's or Spearman's method where appropriate. All reported statistics are labeled with the test used. Box and whisker plots have min-max whiskers, 25th to 75th percentile boxes, and the central line is the median. The probability of $\mathrm{AAD}$ given at least $\times$ oPDs was calculated using the formula: $P\left(A D \mid \sum P D_{i} \geq x\right)=\frac{P\left(A D \cap \sum P D_{i} \geq x\right)}{P\left(\sum P D_{i} \geq x\right)}$. For assessment of $O A D$ probability given oPD on a given stimulus pulse $n$, we used the formula for conditional probability: $P\left(A D \mid P D_{n}\right)=\frac{P\left(A D \cap P D_{n}\right)}{P\left(P D_{n}\right)}$. For assessment of $O P D_{150}$ probabilities given the results of previous trials we used the formula: $P\left(P D_{150} \mid P D_{n-\text { back }}\right)=\frac{P\left(P D_{150} \cap P D_{n-\text { back }}\right)}{P\left(P D_{n-\text { back }}\right)}$. Fisher's exact test was used to compare proportions.

\section{Results}

To explore network propagation of optogeneticallyinduced seizures and PD activity, we developed a multisite satellite array system consisting of individually placed microwires in perihippocampal structures and an optrode above CA1. Targets included PFC, AMTh, Ent, DG, Sub, hippocampal area CA3, and area CA1 bilaterally (CA1-L and CA1-R; Fig. 1A). These recording sites provide coverage of areas demonstrated to be strongly activated by optogenetic stimulation of CA1 using fMRI (Weitz et al., 2015). Our preparation yielded high quality chronic recordings of multiple interconnected areas, allowing us to assess the impact of optogenetic stimulation on the network. By varying the intensity of light stimulation, we 
measured ADTs using train stimuli (OADT), and the unitary PDT using single pulses (oPDT). We present the results of the oADT experiments first to provide context for the oPDT, but it should be noted that prior ADs, and/or exposure to behavioral seizures are not required to obtain oPDT measurements.

\section{Measuring the oADT and opto-kindling}

oADs and behavioral seizures were induced using rhythmic square wave optical stimuli $(6.67 \mathrm{~Hz}, 10-\mathrm{ms}$ pulse, 10-s train); $6.67 \mathrm{~Hz}$ was the lowest frequency that reliably produced an OAD and the longer period $(150 \mathrm{~ms})$ provided sufficient time between pulses to observe the propagation of induced activity throughout the network (Fig. 2B). Stimulus trains were presented every $2 \mathrm{~min}$ at increasing light intensity until an oAD occurred (Fig. $2 A, C$ ). Subthreshold stimulation produced local activation at the stimulation site (CA1), but the evoked activity did not spread to downstream areas (Fig. $2 A$, top inset). The mean oADT was $2.11 \mathrm{~mW}$ (SD 1.12, 95\% Cl [1.08, 3.15], $n=7)$.

Our preparation is configured to stimulate CA1 with minimal damage by situating the optical fiber just above CA1 in visual cortex. In addition to strong expression in CA1, Thy 1 mice also express ChR2 in layer 5 of cortex, raising the possibility that these cells were activated by light backscatter. To verify that CA1 is the relevant site of stimulation for seizure induction, we performed control experiments $(n=2)$ in which the fiber was placed superficially in cortex $(0.5 \mathrm{~mm}$ dorsal to the fiber location in the standard array). Much higher light intensities were required to induce ADs in these animals $(16.58 \mathrm{~mW}$ and $27.86 \mathrm{~mW}$ using a fiber coupled laser), levels sufficient to produce suprathreshold activation of CA1 from this distance, suggesting that activation of cortex is not sufficient to generate $A D s$ and that $C A 1$ is the primary site of activation.

While suprathreshold stimulation produced network wide oPDs following each pulse, high-frequency highamplitude bursts, and $O A D$, occasionally the stimulation intensity just below threshold produced synchronous discharges similar to oPDs on the first few pulses (Fig. 2A, red traces, top). Likely a result of ChR2 desensitization (Lin, 2010), the probability of an oPD decreases with pulse number (Fig. 2C, inset), allowing us to estimate the number of oPDs required for an OAD. We found that the probability of $O A D$ depends on the number of oPDs generated by the stimulus (Fig. 2C), $\mathrm{P}(\mathrm{AD})>0.90$ for $x=8$ oPDs and P(AD) $>0.99$ for $x=17$ oPDs $(n=841$ stimulus trains). This suggests that the $O A D$ is a result of the accumulated effect of closely spaced oPDs possibly related to the accumulation of extracellular potassium (de Curtis et al., 2018). oADs occurred during and immediately after stimulation (Fig. $2 A-C$ ), rather than after a delay, as previously observed with optogenetic seizure induction in motor cortex (Khoshkhoo et al., 2017). The mean oAD duration was $23.1 \mathrm{~s}$ (SD 4.84, 95\% Cls [22.2, 24.0], $n=105$ oADs).

Pathologic high-frequency oscillations (pHFOs; 80-500 $\mathrm{Hz}$ ) have been detected preceding seizures in a number of animal models and in intracranial recordings from humans with epilepsy (Bragin et al., 1999; Staba et al., 2002; Zijlmans et al., 2012). In the majority ( $88 \%, n=105$ oADs) of optogenetically-induced oADs, pHFOs occurred in CA3, DG, and CA1 (Fig. 2A,B). A non-zero phase shift was observed between these areas, suggesting synaptic or ephaptic transmission, rather than volume conduction (Shivacharan et al., 2019; Fig. 2B). The mean latency from the start of the stimulation to burst onset was $6.42 \mathrm{~s}$ (SD $2.75,95 \% \mathrm{Cl}[5.87,6.97], n=97$ oADs). Epileptiform bursts ranged in frequency from 150 to $400 \mathrm{~Hz}$ (6.6- to 2.5 -ms intraburst intervals) and were detected in all animals tested (7/7). These bursts were similar (in terms of amplitude and frequency) to patterns previously observed in perforant path-stimulated or kainate-treated rats (Bragin et al., 1997, 2004, 2005).

\section{Opto-kindling and the emergence of behavioral seizures}

Using this thresholding procedure, we took a subset of animals $(n=7)$ through an opto-kindling procedure based on those performed previously with electrical stimulation (Goddard et al., 1969; Racine, 1972a; Fig. 2D,E). Threshold oADs were presented daily for $15 \mathrm{~d}$. Traditional electrical kindling results in reduced thresholds and increased behavioral severity (Racine, 1972a). In contrast, the oADT remained stable (uncorrelated with presentation \#) over the course of kindling $(r=0.0865, p=0.759$, ns, $n=7$; Fig. 2D), in agreement with previously reported optogenetic seizure thresholds obtained by varying stimulus number (Khoshkhoo et al., 2017). The mean oADT during kindling was $1.99 \mathrm{~mW}$ (SD 0.827, 95\% Cl [1.22, 2.75], $n=$ 7). Repeated $O A D$ induction was correlated with increasingly severe behavioral seizures as quantified using a modified Racine scale $(r=0.963, p<0.0001, n=7$; Fig. $2 E$ ). Animals progressed to stage five seizures after $9.6 \mathrm{~d}$ (SD 2.4, 95\% Cl [7.4, 12], $n=7$ ), considerably faster than corneal or hippocampal kindled mice (Rowley and White, 2010; Stover et al., 2017), but slower than kindling of piriform cortex (Mclntyre et al., 1993). The stereotypical behavioral expression (semiology) of the seizure was similar to that observed with electrical kindling (Racine et al., 1972; Kairiss et al., 1984). Spontaneous seizures were not observed during or following the 15-d kindling period.

\section{oPD induction and threshold measurement}

Given the close relationship between the appearance of multiple network wide oPDs following stimulation and subsequent oADs, we sought to determine whether the OPD itself was a sufficient indicator of the OADT and therefore, a potential measure of OADT without the need for $O A D$ induction.

Single pulse optogenetic stimulation of CA1 at a sufficient intensity (mean $2.85 \mathrm{~mW}$, SD $0.248,95 \% \mathrm{Cl}$ [2.343.36], $n=30$ mice) produced nearly synchronous PDs across the hippocampal and perihippocampal network (Fig. $3 A, B)$. The largest amplitude responses were observed in DG and CA3, as well as contralateral CA1. These unitary oPDs closely resembled those induced in the first few pulses of the optical stimulus train used in the 
A
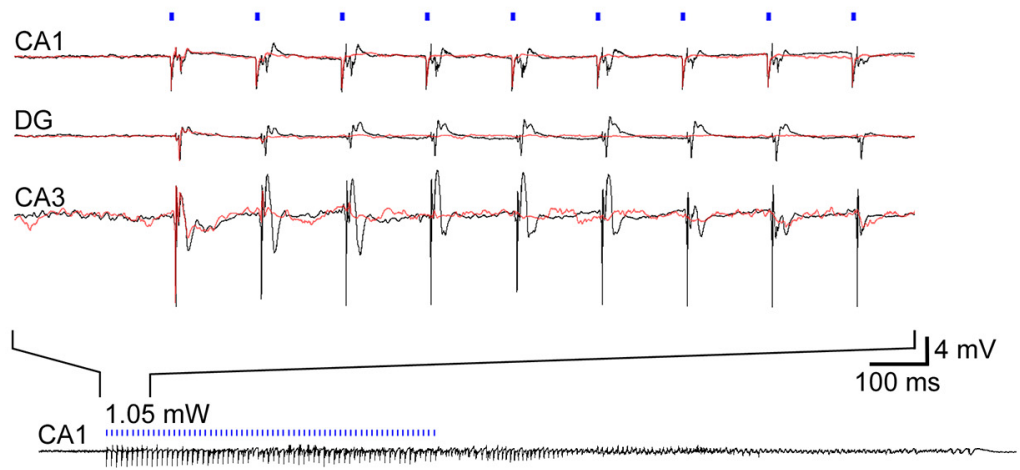

DG

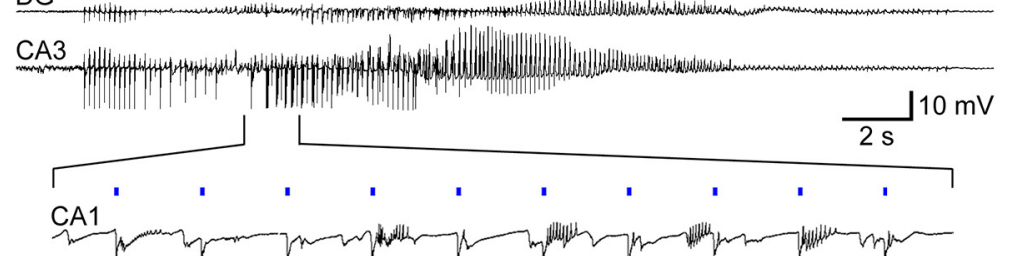

DG


C
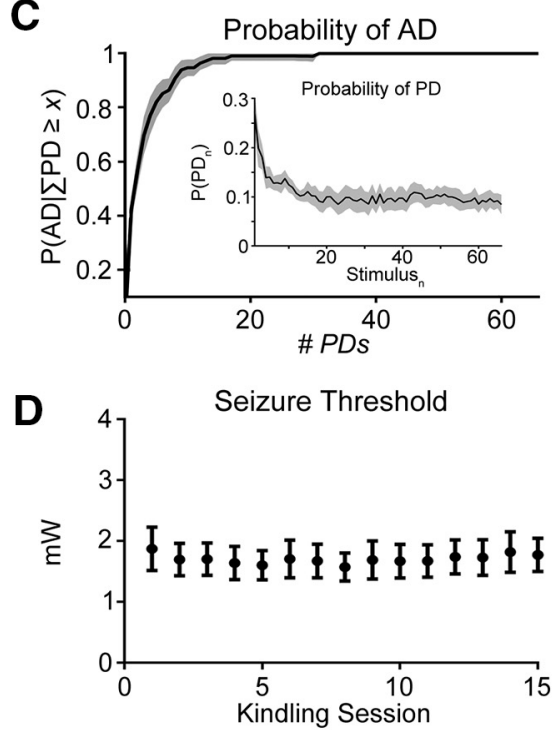

E

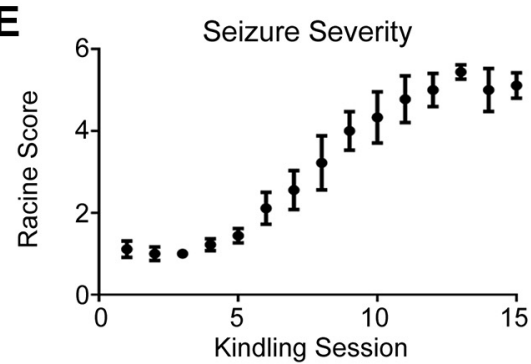

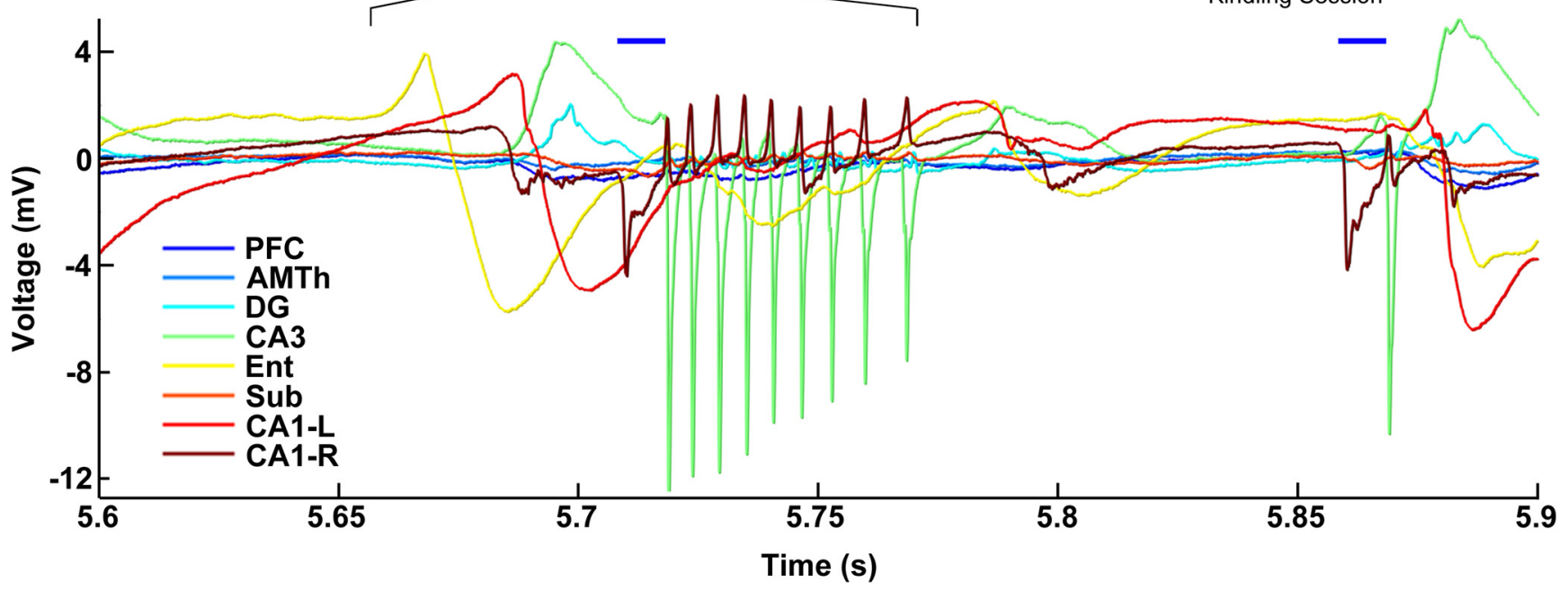

Figure 2. Optogenetic train stimulation produces an AD. Kindling with daily oADs results in an overt behavioral seizure. $\boldsymbol{A}$, Representative example of an optically-evoked AD. Top traces, Suprathreshold stimulation levels (for AD) produce network wide PDs (black traces). At subthreshold intensity levels, activation was observed only at the stimulation site (CA1-R; red traces). Middle traces, Zoomed out view of oAD. Bottom traces, pHFOs during oAD induction. $\boldsymbol{B}$, oADs involve pHFOs across multiple sites with a non-zero phase lag. $\boldsymbol{C}$, The probability of AD given at least $\times$ PDs occurring during the stimulus train. Inset, The overall probability of a PD on each pulse of the train, including subthreshold stimuli. Probabilities were calculated for each animal and the mean is displayed with $95 \%$ Cls, $n=7$ animals. $\boldsymbol{D}$, Seizure threshold remained stable throughout the kindling period. $\boldsymbol{E}$, Behavioral seizure severity increased with each $A D$ and was correlated with stimulation number.

oADT procedure, as well as spontaneous type-2 IIS, observed in AD-exposed animals (Fig. $3 A$ ).

To precisely measure the oPDT, we developed a novel optogenetic intensity-response curve procedure that takes advantage of the all or none transition between the sub and suprathreshold response at recording sites downstream of the optogenetic stimulation to accurately detect the occurrence of oPDs (Fig. 3). Repeated presentation of the intensity-response curve revealed considerable variability in the response (OPD vs no oPD) given a 
A

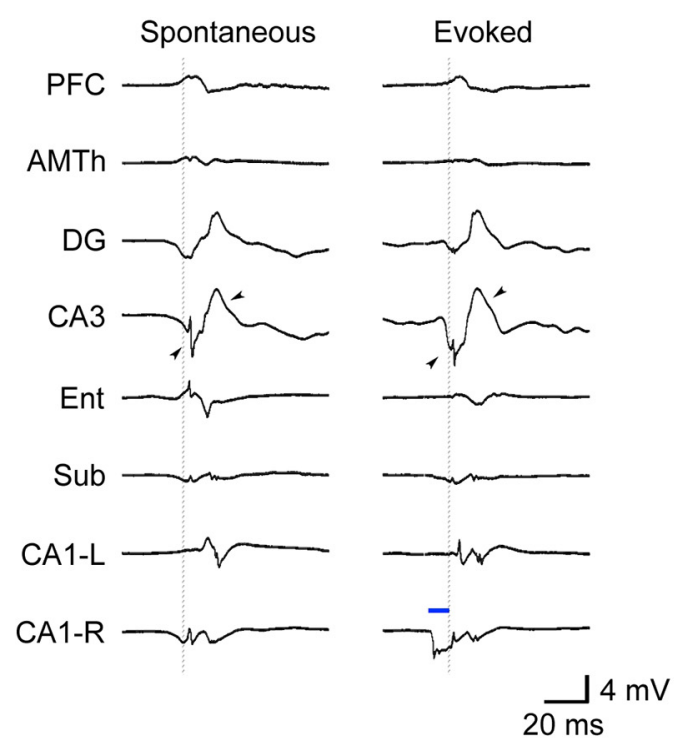

C
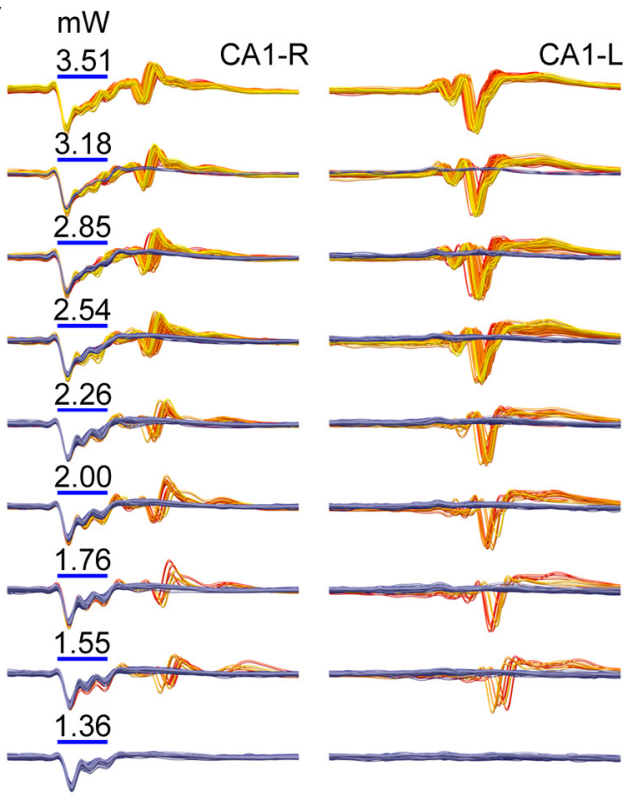

B

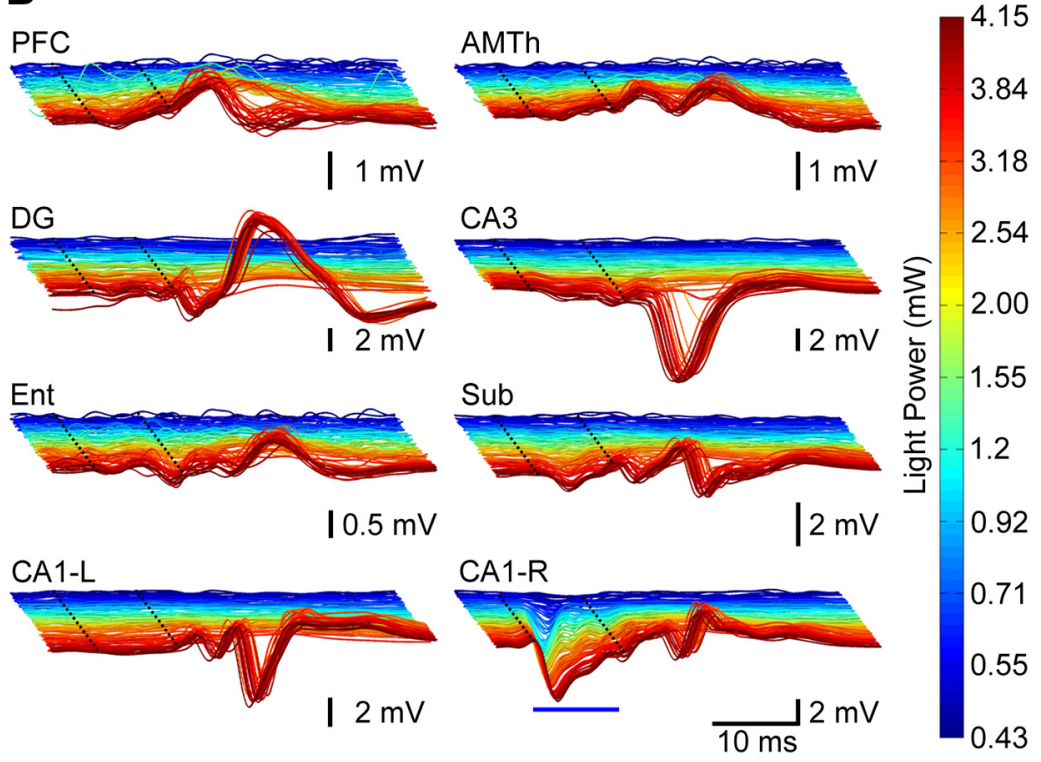

D
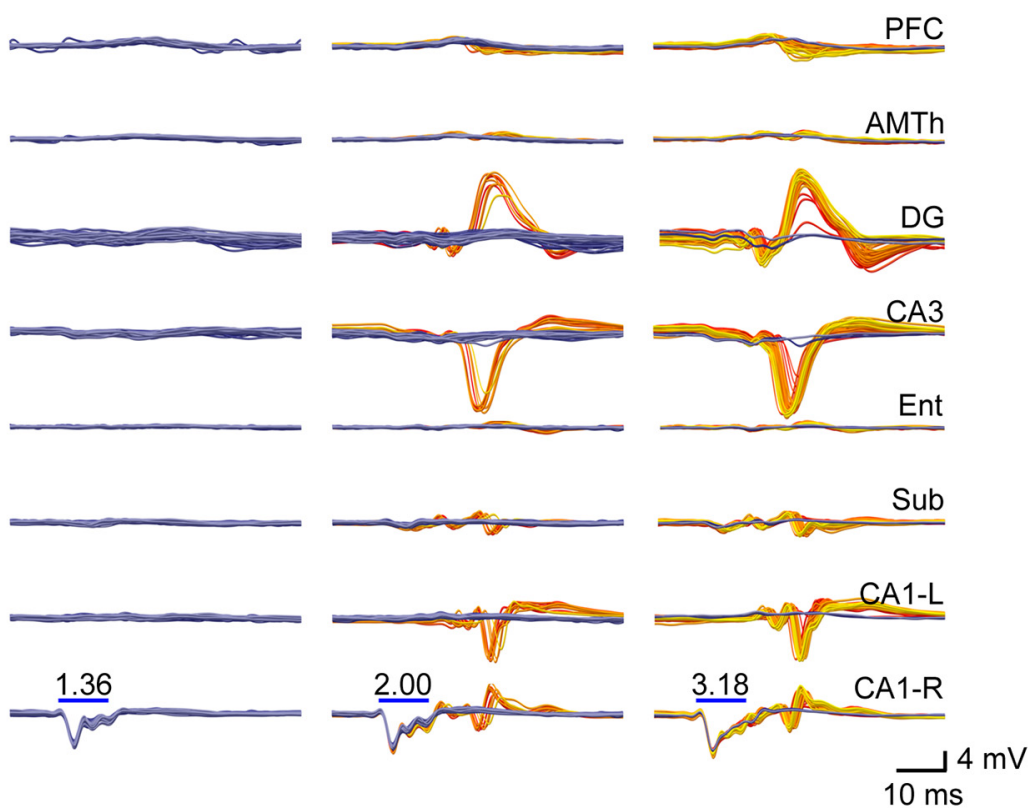

Figure 3. Optogenetic stimulation produces network wide PDs that closely resemble spontaneous IIS with a probability that increases with light intensity. A, Example comparing spontaneous IIS to oPDs. Spontaneous IIS are characterized by near synchronous activation in DG, CA3, and CA1-R, and delayed activation in CA1-L. Evoked discharges are led by activation in CA1 (stimulation site) followed by near synchronous activation of DG, CA3, and CA1 with a latency of $\sim 10 \mathrm{~ms}$. Note similar timing and wave shape between stimulus evoked and spontaneous discharges (arrowheads). Blue bars indicate onset and duration of light stimulus in CA1. ISI $=3$ S. $\boldsymbol{B}$, Evoked network activity produced by optogenetic stimulation of area CA1 (right side) at varying light intensities in a representative animal (different from that depicted in $\boldsymbol{A}$ ). Note large amplitude oPDs evoked at higher intensities. Dotted lines indicate the beginning and end of the light pulse. $\boldsymbol{C}, \boldsymbol{D}$, Probability of oPD occurrence in downstream sites, rather than amplitude, increases with light intensity at the stimulation site. In area CA1-L, a longer latency response is accompanied by a high amplitude PD. The gold colored traces are those in which a PD was detected, the blue are traces where it was absent. Each plot is an overlay of 60 trials, and the color gradient indicates chronological order (dark blue/red for early trials, light blue/yellow for late trials). oPD occurrences: $0 / 60$ at $1.36 \mathrm{~mW}, 11 / 60$ at $2 \mathrm{~mW}, 58 / 60$ at $3.18 \mathrm{~mW}$. ISI $=3 \mathrm{~s}$. Scale bars in $\boldsymbol{D}$ also apply to $\boldsymbol{C}$.

particular stimulus intensity (Fig. 3C,D). However, we found analyzing the probability of an OPD given stimulus intensity $\mathrm{x}, \mathrm{P}\left(\mathrm{oPD} \|_{\mathrm{x}}\right)$, allowed for a more robust estimation of threshold.
To generate the oPD probability curve we used twenty intensity levels presented in repeated blocks. Stimuli were presented in random order without replacement so that each stimulus intensity level was presented once per 
A

Optogenetic Intensity Response

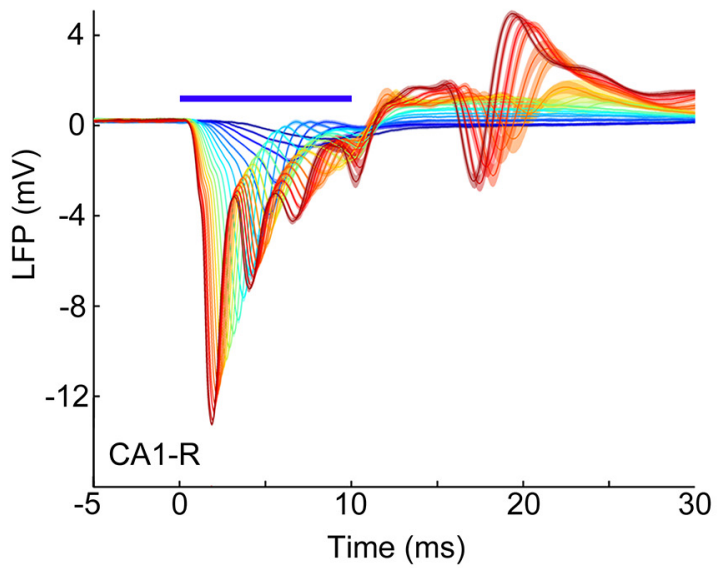

B

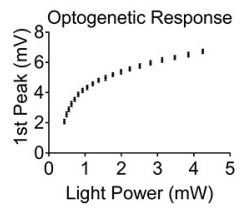

C

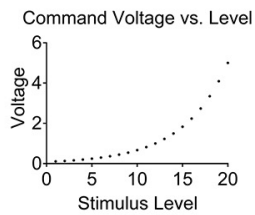

D

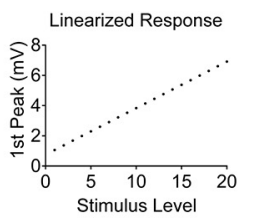

Level $\mathrm{mW}$

$20-4.15$

15

3.18

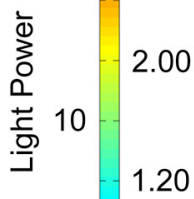

5

0.71

$1-0.43$

\section{E}



G

Max RMS Sorted by Magnitude

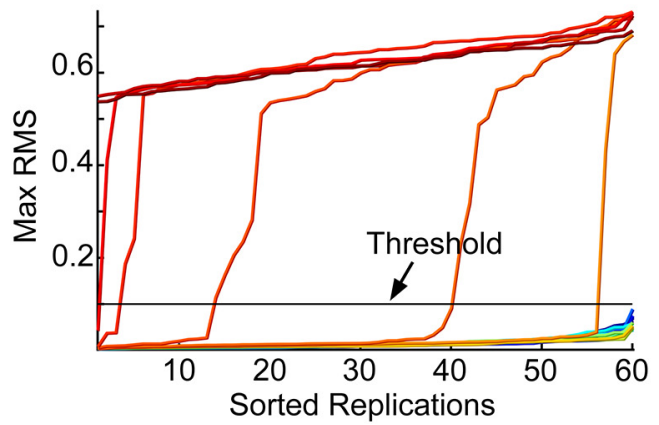

$\mathbf{F}$

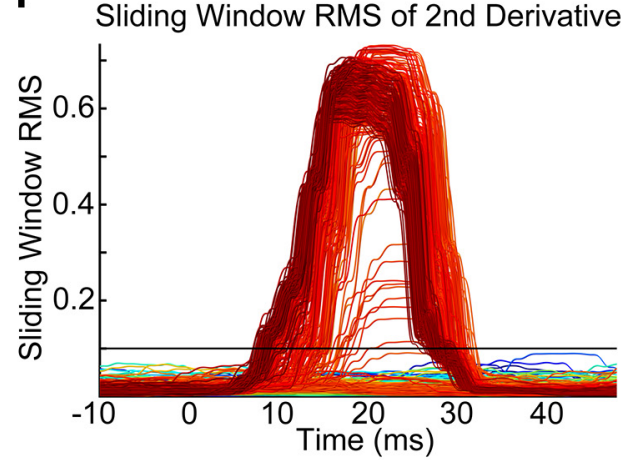

H

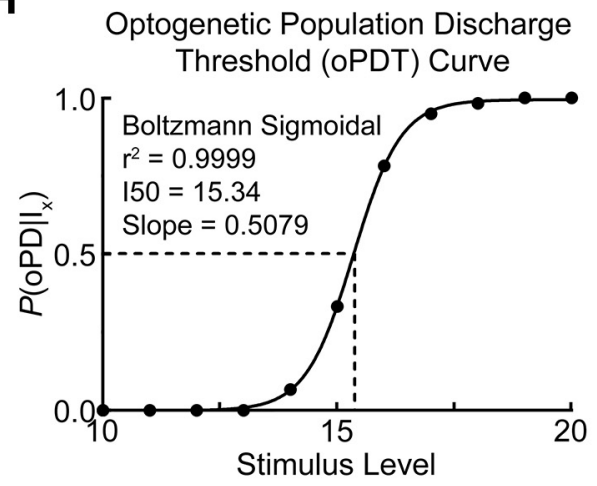

Figure 4. Summary of the oPDT procedure. $\boldsymbol{A}$, Average LFP response to optogenetic activation in CA1 at varying light intensities. Shaded bars $=95 \%$ Cls. $\boldsymbol{B}$, The short latency LFP response was used as an approximation of ChR2-mediated current to generate a light intensity-response curve. Mean and SD are displayed. C, A series of light intensities was chosen to produce a linearized optogenetic response $(\boldsymbol{D})$. $\boldsymbol{E}$, The network propagation of evoked activity from the stimulation site (CA1-R, blue bar) to CA1-L. Individual replicates plotted as bandpass filtered $(5-300 \mathrm{~Hz})$ traces. Colors correspond to the level of the light stimulus (shown in mW on color bar); 20 levels $\times 60$ replicates $=1200$ total stimuli. ISI $=3 \mathrm{~s}$. Note high amplitude PDs. $\boldsymbol{F}$, Sliding window RMS of the 2 nd derivative calculated from $\boldsymbol{E}$. Horizontal line indicates the threshold. G, Max RMS (within time window) for each light level sorted by magnitude. Threshold is set in the steep part of the curve. $\boldsymbol{H}$, oPD ratio (oPDs/total stimuli) plot fit by the Boltzmann sigmoid allows for calculation of an 150 , or the LED power at which $50 \%$ of the stimuli produce a oPD.

block. Stimulus order was independently randomized for each block. oPD probability was then estimated using multiple replications of stimulus blocks. The intensity levels were selected to linearize the optogenetic response as measured by the mean amplitude of the first peak at the stimulation site, likely a reflection of the interaction be- tween the ChR2-mediated current and dendritic voltagegated $\mathrm{Na}^{+}$currents (Fig. 4A-D). Network oPDs were detected by thresholding a sliding window RMS of the 2nd derivative of the peri-stimulus activity (Fig. 4E-G).

The oPD occurs across the network, and therefore, any channel or combination of channels can be used for oPD 
detection, including the long latency response at the stimulation site; however, we found that contralateral CA1 provided the greatest separation between subthreshold and suprathreshold responses. The sub-supra separation was visualized by plotting the sorted peak values of the RMS for each level (Fig. 4G). Good separation produces a steep transition with few intermediate values. This plot is also useful for setting the threshold and the steepness of the transition reduces the detection bias introduced by threshold selection. As a result, the oPDT curve is robust to any choice of threshold within the steep transition region of the sorted peak RMS plot.

Once oPDs have been detected, the proportion of oPDs to total stimulus presentations at each level can then be plotted to generate an oPDT curve. We then fit the data with the Hodgkin and Huxley formulation of the Boltzmann distribution and calculated the 150 , or the intensity at which the probability of oPD was $50 \%$ (Hodgkin and Huxley, 1952; Fig. 4H). Expressing the 150 in the arbitrary linearized scale (1-20 levels) is convenient for making comparisons, however, it can easily be converted into power $(\mathrm{mW})$ or irradiance $\left(\mathrm{mW} / \mathrm{mm}^{2}\right.$; Fig. $\left.4 B-D\right)$. Although the linearized scale improves the fit of the Boltzmann, substituting $\mathrm{mW}$ also produces a sigmoidal curve. Using an arbitrary scale and baseline normalization allows for comparisons between animals even when the relationship between power output and optogenetic response varies. In our experience, the variability in baseline 150 between animals, SD $=3.41$ levels ( $n=20$ animals), was larger than the mean 150 variability within animals, mean $S D=$ 1.10 levels ( $n=3-10$ baselines per animal). Since ChR2 expression patterns are preserved between animals, it is likely that between-animal differences are due to variations in the surgical preparation and the transmission efficiency of the implanted fiber.

\section{Relationship between the oPDT and oADT}

Our analysis of the OADT revealed that multiple oPDs must be evoked by the train stimulus to generate an $O A D$ (Fig. 2C). We compared the oADT and the oPDT measured in the same animals using the same chronically implanted fiber. We found that the oADT was correlated with pre-kindling 150 across animals with a slope approaching 1 (1st seizure: lin. reg. slope: $1.05,95 \% \mathrm{Cl}$ $[0.677,1.42]$, Pearson's $r=0.956, p=0.00078, n=7$; average seizure: lin. reg. slope: $0.830,95 \% \mathrm{Cl}[0.462$, 1.20], Pearson's $r=0.933, p=0.0021, n=7$; Fig. 5A). This finding combined with the fact that train stimuli subthreshold for the OPD also failed to produce an OAD, indicate that the oPDT and the OADT are equivalent in terms of light intensity delivered from the same implanted fiber, because both require the oPD.

\section{Changes in excitability shift the oPD curve}

To test the hypothesis that the $\mathrm{P}(\mathrm{oPDII})$ changes with the balance of excitation and inhibition, we used a wellknown chemoconvulsant drug, pentylenetetrazol (PTZ), in non-kindled animals. Despite its ability to induce acute seizures, PTZ does not produce a shift in the electrical ADT (Karler et al., 1989). In contrast, the oPDT was sensitive to PTZ at sub-convulsive doses $(20 \mathrm{mg} / \mathrm{kg})$. The 150 was significantly shifted to the left relative to baseline (baseline $=16.4$ levels, SD 0.943, 95\% Cl [15.4, 17.4], PTZ $=14.5$ levels, SD $0.949,95 \% \mathrm{Cl}[13.5,15.5], p=$ $0.00041, n=6$; Fig. $5 A, B$ ), which indicated a reduction in threshold.

Although the antiepileptic drug levetiracetam (LEV) failed to show efficacy in the traditional MES and subcutaneous PTZ acute seizure models (Löscher, 2011), it does increase the ADT in kindled rats (Löscher et al., 2000). Pre-treatment with LEV $(40 \mathrm{mg} / \mathrm{kg})$ partially reversed the leftward shift produced by subthreshold PTZ and returned threshold to near baseline levels (PTZ+LEV $=15.7$ levels, SD 1.11, 95\% Cl [14.5, 16.8]; baseline vs PTZ, $p=0.00043$, baseline vs PTZ+LEV, $p=0.12$, PTZ vs PTZ+LEV, $p=0.0034, n=6$ repeated-measures ANOVA with Tukey's correction for multiple comparisons; Fig. $5 A, B)$. Saline injection did not significantly shift the curve (baseline vs saline, $p=0.99, n=7$, paired $t$ test).

By breaking the stimulus period into bins of presentation blocks, $\mathrm{P}\left(\mathrm{oPD} \|_{\mathrm{x}}\right)$ can be measured over time. Administration of subthreshold PTZ (intraperitoneally) produced a rapid shift in excitability that partially recovered by $\sim 60$ min after injection (Fig. 5F), compared to saline, consistent with the pharmacokinetic curve of PTZ (Yonekawa et al., 1980). For this example, six block bins were used to estimate the 150 at 2-min intervals [six blocks $\times 20$ stimuli per block $\times 1$-s interstimulus interval $($ ISI $)=120 \mathrm{~s}$ ), but higher temporal resolution is possible by decreasing the bin size and/or the number of stimuli per block.

\section{Stability and reliability of the oPDT}

We assessed the reliability of oPDT measurements, in terms of short- and long-term stability, by analyzing baseline data. Two ISIs ( 1 and $3 \mathrm{~s}$ ) were used to produce intensity-response curves. This allowed for a comparison of the stability of baseline 150 values generated using each protocol, with the caveat that the data came from different animals. Baselines were selected for further analysis if they were collected in naiive animals (pre-kindling, pretreatment; $n=67$ sessions in 13 animals for 1 -s, $n=41$ sessions in 17 animals for 3 -s interval).

First, we looked at the test-retest reliability of measurements (20 levels, 60 replications each) taken on consecutive days (Fig. 6A). The measured I50s were consistently reliable with an overall correlation coefficient $>0.85$ (1-s interval: $r=0.917,95 \% \mathrm{Cl}[0.705,0.979], p<0.0001, n$ $=11$ pairs, 3-s interval: $r=0.856,95 \% \mathrm{Cl}[0.446,0.969]$, $p=0.0032, n=9$ pairs, Pearson's).

Mono-synaptic stimulation of CA1 afferents at 1-s intervals has been shown to induce long-term depression (LTD) in vivo (Thiels et al., 1994; Oliet et al., 1997; Massey and Bashir, 2007). To determine whether the multisynaptic 150 was drifting over time in our preparation, we broke each 60 -block session into $10 \times$ six-block bins and calculated intermediate 150 values normalized by subtracting the overall session 150 (Fig. 6B). Following a transient increase for both, session 150 values gradually increased for the 1-s interval and decreased for 3-s interval (1-s interval: slope greater than zero, slope: 0.00442 [0.00206, 0.00678], $p=0.0031$, 3-s interval: slope less 
A

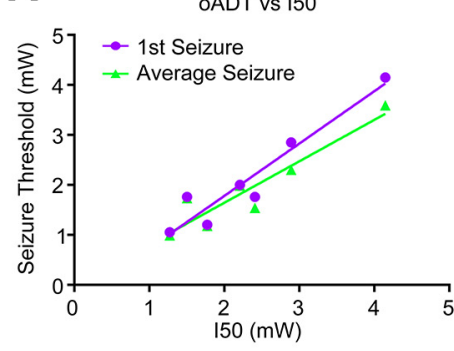

B

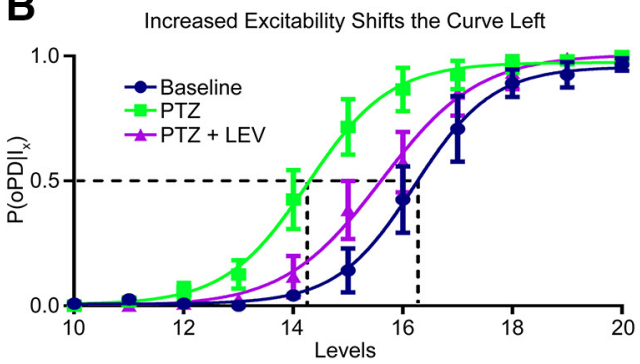

c

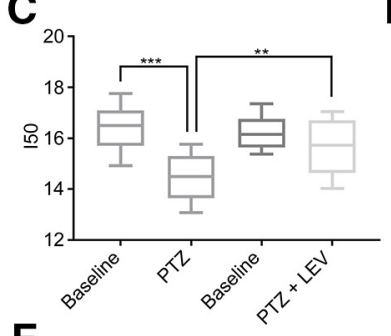

D



E

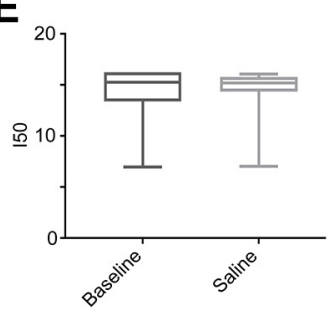

F

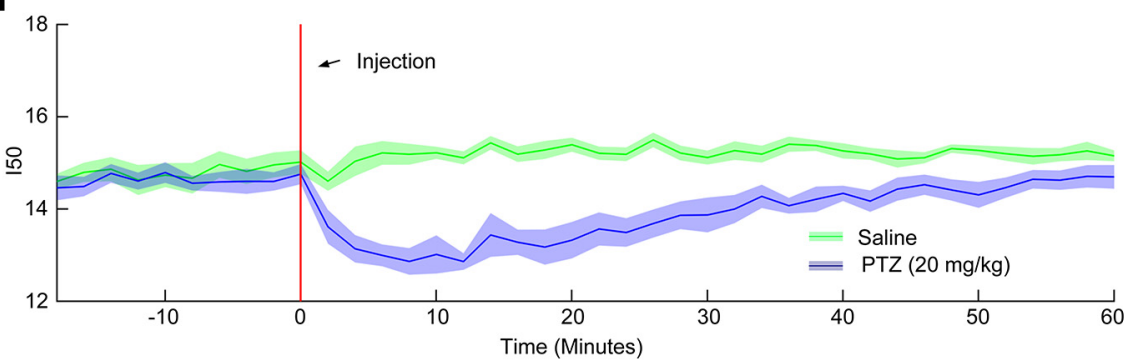

Figure 5. The I50 is sensitive to changes in network excitability. $\boldsymbol{A}$, The relationship between pre-seizure I50 and the 1st oADT (purple) or the average oADT throughout 15 kindling sessions (green). $\boldsymbol{B}, \boldsymbol{C}$, The GABAa antagonist PTZ (20 mg/kg) shifts the oPD curve leftward and treatment with the anticonvulsant drug LEV $(40 \mathrm{mg} / \mathrm{kg})$ partially reverses the shift; $n=6$ animals; $* * * p=0.00043, * * p$ $=0.0034$. Curve error bars indicate the $95 \% \mathrm{CI} . \boldsymbol{D}, \boldsymbol{E}$, Handling and intraperitoneal saline administration did not significantly shift the oPD curve compared to baseline (paired $t$ test, $n=7$ ). $\boldsymbol{F}$, 150 measurements reveal the time course of PTZ-induced hyperexcitability (disinhibition). Plot of the 150 over time. Six block bins, $n=9$ presentations of each condition (three trials $\times$ three animals). Shaded area is mean $\pm 95 \% \mathrm{Cl}$.

than zero slope: $-0.0101[-0.0158,-0.00441], p=$ 0.0040 , linear regression of the means excluding the first 12 replicates).

This gradual shift in the 150 through time could be a result of plasticity in the network but also ChR2 desensitization at the stimulation site. All ChR variants exhibit desensitization with varying degrees of reduction in peak photocurrents following repeated activation (Lin, 2010; Williams et al., 2013). We checked for ChR2 desensitization by measuring the peak amplitude (session min/max normalized) of the optogenetic response at the stimulation site over time (Fig. 6C). We found that the response amplitude is reduced (3\%) within the first $4 \mathrm{~min}$, likely an effect of desensitization, after which it increased slightly (1-s interval: slope greater than zero, slope: $1.16 \times 10^{-4}$, $95 \% \mathrm{Cl}\left[7.62 \times 10^{-6}, 2.25 \times 10^{-4}\right], p=0.037,3-\mathrm{s}$ interval: slope greater than zero, slope: $7.63 \times 10^{-4}, 95 \%$ $\mathrm{Cl}\left[6.52 \times 10^{-4}, 8.75 \times 10^{-4}\right], p<0.0001$, linear regression of the means excluding the first 12 replicates). Overall, the baseline drift in the response amplitude and the 150 over time was small relative to the effects of subthreshold PTZ, for instance (Fig. 5B,F). Nevertheless, drift must be accounted for in the interpretation of experimental results and all results should be compared to a vehicle control (Fig. 5E,F).

Next, we examined possible short-term effects of stimulation on the $\mathrm{P}\left(\mathrm{oPD} \|_{\mathrm{x}}\right)$ and assessed trial independence. The extent of ChR2 desensitization depends on the strength of previous activation and higher intensity stimuli are expected to produce greater desensitization than lower intensity stimuli. Since the stimuli are presented in random order, we were able to quantify this effect by measuring the extent of desensitization produced by each stimulus pair. We measured the peak amplitude of the response to a stimulus (level 10) following each of the other stimulus levels (Fig. 6D). There was a small reduction in amplitude of the response for strong preceding stimuli (1-s interval: slope less than zero, slope: -0.00208 , 95\% Cl [-0.00271, -0.00145], $p<0.0001,3-s$ interval: slope not different from zero, slope: $-3.58 \times 10^{-4}, 95 \% \mathrm{Cl}$ $\left[-9.56 \times 10^{-4}, 2.40 \times 10^{-4}\right] p=0.22$, ns, linear regression of the means). to determine whether this change in amplitude translated into a shift in the oPD probability, we calculated the oPDT probability at or near the 150 for each preceding stimulus (Fig. 6E). A subset of the data was selected for this analysis restricted to those sessions with 
A
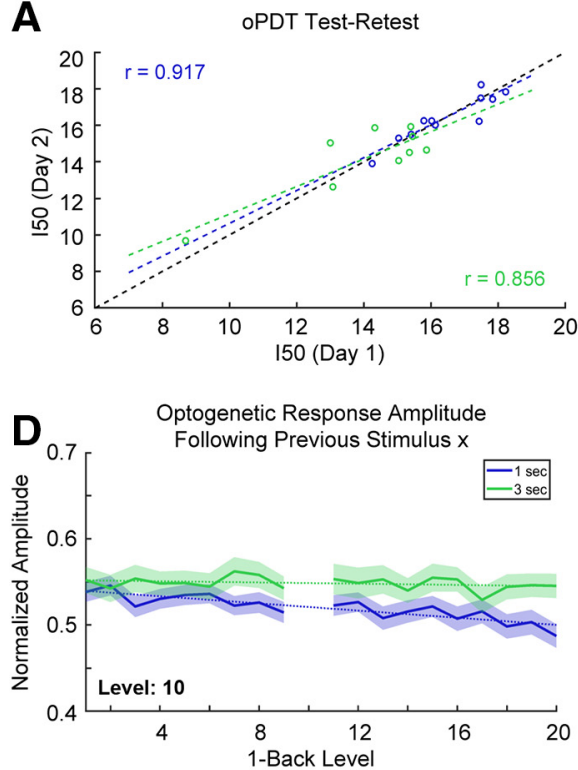

B
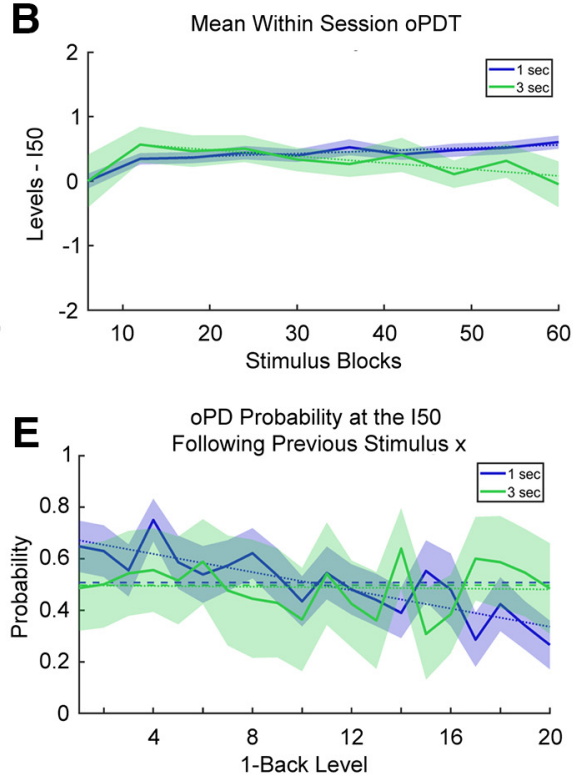
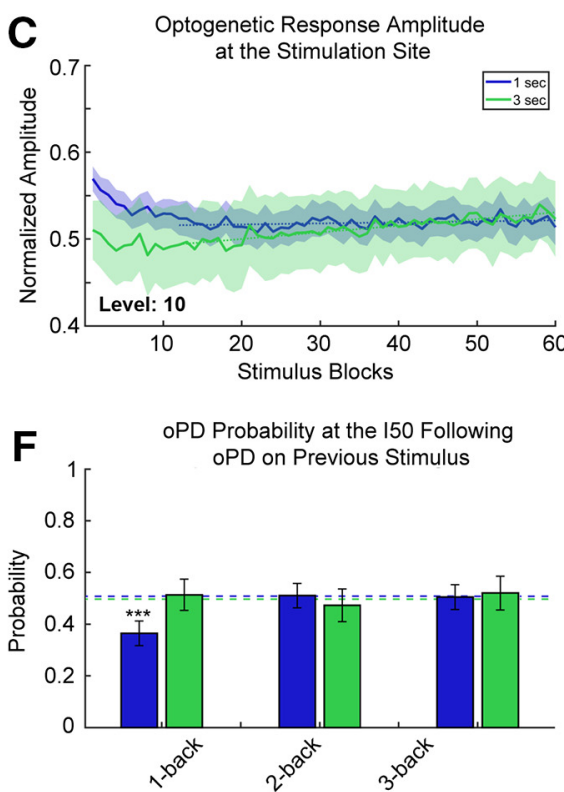

Figure 6. Stability and reliability of the oPDT. $\boldsymbol{A}$, Test-retest comparison of session I50s on consecutive days; $n=11$ pairs for 1 -s interval and $n=9$ pairs for 3-s interval. Each session 150 is calculated from 60 replicates. Dashed black line indicates the diagonal. $\boldsymbol{B}, 150$ is relatively stable over the course of a session. Mean normalized intermediate I50s (six replicate bins) for 1- and 3-s ISIs. Each stimulus block consisted of 20 intensity levels presented in random order. Order was randomized independently for each block. Session duration is $20 \mathrm{~min}$ for the 1-s ISI and $60 \mathrm{~min}$ for the 3-s ISI; $n=67$ and $n=41$ sessions for the 1- and 3-s ISIs, respectively. Shaded bars indicate $95 \% \mathrm{Cl}$. Dotted lines indicate best fit (linear regression) excluding blocks 1-12. C, Optogenetic response amplitude is reduced within the first 5 min of recording, likely due to ChR2 desensitization. Values were transformed via min-max normalization for the entire curve. Same dataset as in $\boldsymbol{B}$. Dotted lines indicate best fit (linear regression) excluding blocks 1-12. $\boldsymbol{D}$, The optogenetic response amplitude at the stimulation site is reduced following high intensity stimuli (1-back stimuli are plotted on the $x$-axis). The $y$-axis indicates the mean normalized response amplitude at level 10 . Same dataset as in $\boldsymbol{B}$. $\boldsymbol{E}$, The probability of an oPD at the 150 depends on the intensity of the previous stimulus for 1-s intervals. Dashed lines indicate the overall probability of an oPD at a level within \pm 0.25 of the 150. Dotted lines indicate best fit (linear regression); $1 \mathrm{~s}: n=29$ sessions, 1740 trials, $3 \mathrm{~s}: n=10$ sessions, 600 trials. $\boldsymbol{F}$, oPDs that occur $<2 \mathrm{~s}$ prior have a suppressive effect on the probability of an oPD at the I50. Dashed lines indicate the overall probability of an oPD at a level within \pm 0.25 of the 150 . Error bars indicate the $95 \% \mathrm{Cl}$. Same subset as in $\boldsymbol{E}$.

150 values that were near a presented stimulus level (within \pm 0.25 levels of a whole number; $1 \mathrm{~s}: n=29$ sessions, 1740 trials, $3 \mathrm{~s}: n=10$ sessions, 600 trials). This allowed us to determine whether deviations from chance were related to the stimulus order. The probability of oPD was negatively associated with the intensity of the previous stimulus for the 1-s but not 3-s interval (1-s interval: slope less than zero, slope: $-0.0177,95 \% \mathrm{Cl}[-0.0232$, $-0.0121], p<0.0001,3-s$ interval: slope not different from zero, slope: $-8.37 \times 10^{-4} 95 \% \mathrm{Cl}[-0.008,0.007], p=$ 0.82). This suggests that the reduction in amplitude (Fig. $6 D)$ translates into a reduction in oPD probability.

Higher intensity stimuli are also more likely to produce an oPD, so we checked for effects of the oPD itself on the oPD probability at the 150 . We calculated the conditional probability of an oPD at stimulus levels within \pm 0.25 of the I50 (where the probability of an oPD should be close to chance), given an oPD on the nth previous stimulus (any level). Each $n$-back probability was calculated independently. We found a strong suppressive effect of a previous PD for the 1-back stimulus with a 1-s ISI compared to the overall probability of an oPD at the $150(p<0.0001$, Fisher's exact test, corrected for multiple comparisons using the Holm-Sidak method). PD probability did not differ significantly from chance at 2- and 3-back for the
1 -s interval $(p=0.91$ and $p=0.32$, respectively, Fisher's exact test, corrected). PD probability remained at chance for 1-, 2-, and 3-back for the 3-s interval $(p=0.91, p=$ 0.51 , and $p=0.45$, respectively, Fisher's exact test, corrected). Therefore, an interval of $>2 \mathrm{~s}$ is expected to be sufficient to produce independent trials and the 1-s interval is expected to produce I50s that slightly overestimate the oPDT, likely due to a combination of ChR2 desensitization and after-hyperpolarization produced by the oPD. For this reason, it is important to compare measurements to baselines collected using the same protocol with the same ISI. It is important to note that all of the above measurements were taken from awake behaving animals and include random variation due to changes in ongoing activity. Taken together, these results indicate that the oPDT curve offers exceptional precision and reliability and as such provides a new clear window into the excitability state of the intact brain.

\section{Discussion}

Neuronal activity occurs on a background of synaptic and intrinsic excitability governed by the biophysical properties of the component cells, synaptic plasticity, and the control of these parameters by internal homeostasis and brainstem modulatory systems (Sterling and Laugh- 
lin, 2015). The complex dynamics of neural circuitry makes it difficult to predict excitability from discrete measurements in reduced preparations, and obtaining direct measurements in behaving animals is technically challenging (Petersen, 2017). Changes in excitability relevant to seizure susceptibility are not fully captured by measurements of individual contributing factors and determining how these factors should be combined to define network excitability is a non-trivial problem. Using a novel light intensity-response procedure, we have developed and validated a new quantitative estimate of network excitability state based on PD probability. Network PDs are an unambiguous indicator of the transition from normal to abnormal functional states; by mapping the probability distribution of oPDs as a function of input magnitude, we derive a surrogate measure of network excitability, the 150, that depends not only on the excitability of the population of cells directly stimulated, but also on the receiving cells in the rest of the network. This approach has several important features: first, combining optogenetic modulators with a high precision LED light source allows for tighter control over induced currents in specific cell populations than previously possible with electrical stimulation; second, our multi-site recording technique allows us to simultaneously induce and monitor PDs as they propagate throughout the network, critical for unambiguous classification; third, our chronic preparation permits tracking of excitability dynamics over multiple timescales, from minutes to months; and finally, because the OPDT procedure does not produce seizures and the baseline I50 is relatively stable over time, pharmacological or molecular interventions can be tested within subjects, greatly increasing the ability to detect functional changes as a result of genetic and/or pharmacological manipulation.

The electrical ADT has been used extensively as a measure of seizure threshold (Löscher, 2017). In many ways, the oADT is the optogenetic equivalent of the electrical ADT, both produce similar acute ADs and repeated presentations lead to behavioral seizure (kindling). Although seizures are an unmistakable sign that a threshold has been crossed, they also produce long lasting effects on the brain, including widespread changes in gene expression (Altar et al., 2004). In contrast, the oPDT does not produce seizures, nor kindling, and therefore can be used to measure thresholds over time allowing within-subjects comparisons free from the confounds of seizure exposure. This property may allow the oPDT to be used to track changes in excitability in models of epileptogenesis as a way to gain insight into mechanisms and measure the effectiveness of various pharmacological and molecular interventions.

Previously optogenetic seizure thresholds have been determined by varying the number of stimulus bouts (Khoshkhoo et al., 2017). The oADT represents the first example of systematic optogenetic intensity-response curves, using a high-precision LED, to precisely determine seizure thresholds (keeping stimulation frequency, pulse width, and train duration constant). When the oADT and the oPDT are combined, the OADT, in the context of a known oPDT provides additional information about seizure susceptibility. Although the thresholds for both metrics are the same in terms of light intensity, the oADT requires repeated oPD inductions to produce an AD. This suggests that distinct mechanisms are involved in the $O A D$ generation, possibly the accumulation of extracellular $\mathrm{K}^{+}$and the switch to depolarizing GABA (Cossart et al., 2005; Miles et al., 2012; Alfonsa et al., 2015; Buchin et al., 2016). Comparing the results of each approach might allow for identification of drugs and manipulations that prevent $A D$ but do not change baseline excitability, and therefore can be expected to have fewer side effects.

Electrically-evoked potential amplitude has previously been used as a measure of excitability in animal models and patients with epilepsy (Maru and Goddard, 1987; Freestone et al., 2011; Enatsu et al., 2012; Wendling et al., 2016; Keller et al., 2018). However, without knowing the details of underlying synaptic currents and their influence on the LFP, it is difficult to estimate excitability from amplitude alone given that somatic inhibition and dendritic excitation produce similar sink/source patterns (Buzsáki et al., 2012; Hales and Pockett, 2014; Herreras, 2016). Because network wide PDs are readily differentiated from subthreshold synaptic potentials, our preparation provides an unambiguous measurement of excitability that does not require knowledge of the sink/source patterns needed to interpret the LFP itself.

Electrical stimulation activates cells and fibers of passage which act on a sparse and widely distributed population of neurons whose identity cannot be predicted ahead of time, nor known with certainty afterward (Histed et al., 2009). In contrast, optogenetic expression patterns can readily be determined histologically and light spread can be accurately modeled based on fiber location and power output. Light spreads out in a cone from the tip of the fiber and drops off quickly with distance in brain tissue due to scattering (Aravanis et al., 2007; Yizhar et al., 2011). As the light intensity increases, cells directly under the fiber will be increasingly depolarized to threshold followed by neighboring cells. Thus, the optogenetic intensity-response curve varies both the magnitude of depolarization in individual cells as well as the overall size of the activated population. Cells in the center that have already reached threshold cannot be depolarized further, in part because ChR2 currents are voltage dependent (Williams et al., 2013). From the perspective of downstream areas, the intensity-response curve varies the number of synchronously active projections emanating from the stimulation site. This is important because, while synchronous firing is an important feature of the function of these circuits, exceeding normal ranges would be expected to produce non-specific propagation of the synchronous discharge when some critical number of downstream cells is induced to fire synchronously.

The sharp transition between sub and suprathreshold activity may reflect a breakdown between the balance of feedforward inhibition and excitation (Buzsáki, 1984; Wahlstrom-Helgren and Klyachko, 2016). If the magnitude of the population EPSP exceeds that of feedforward inhibition, it could produce a highly synchronous dis- 
charge that would propagate to other areas (Johnston and Brown, 1981). This would explain the sensitivity of the oPDT curve to GABA antagonists such as PTZ. In addition to the balance of inhibition and excitation, a number of other functional properties might be expected to modulate the oPDT, the oADT, or both. Synaptic strength determines the threshold for downstream propagation of the synchronous discharge (Nicoll, 2017), intrinsic excitability modulates the responsiveness of downstream cells, which is governed by the relative expression and cellular localization of voltage-gated $\mathrm{Na}^{+}, \mathrm{K}^{+}$, and $\mathrm{Ca}^{2+}$ channels (Graef and Godwin, 2010; Meadows et al., 2016; Lisman et al., 2018), and the regulation of the extracellular space by glia (Devinsky et al., 2013).

The Thy1-ChR2 mice (line 18) used in these experiments express high levels of wild-type ChR2-EYFP in deep (calbindin-negative) pyramidal neurons in CA1 (Arenkiel et al., 2007; Dobbins et al., 2018). Importantly, transgenic animals provide more consistent and specific ChR2 expression patterns than could be achieved with virus injection. Compared to neighboring superficial cells, deep pyramidal neurons in CA1 are more prone to burst firing, have unique input and output pathways, and lack calcium buffering proteins, potentially making them more susceptible to seizure activity (Sloviter, 1989; Mizuseki et al., 2011; Valero et al., 2015). By selectively targeting this population of excitatory neurons the inhibitory population is free to respond, preserving the strong reciprocal relationship they have with the excitatory cells being stimulated, and allowing them to participate in the generation of the synchronous discharge (Cobb et al., 1995; Ellender et al., 2014; Sessolo et al., 2015; Yekhlef et al., 2015; Khoshkhoo et al., 2017; Wang et al., 2017; Chang et al., 2018a; Magloire et al., 2019).

The fact that the evoked discharges initiated in CA1 occurred simultaneously in multiple hippocampal structures supports the hypothesis that synchronous activation of Ent was responsible (Yeckel and Berger, 1990; Avoli et al., 2002). The oPD was most prominent in areas CA3 and DG; reciprocally connected areas prone to hypersynchronous discharge (Traub and Jefferys, 1994). CA3 and DG lead during spontaneous discharges suggesting that synchronous inputs to these areas are responsible for generating the IIS, and optogenetically generated synchronous input from CA1 via Sub and Ent serves as a trigger for the oPD. These results are also consistent with the dentate gate hypothesis, which posits that dentate granule cells, because of their relatively high functional threshold, act as a gate that prevents the propagation of seizure activity into the rest of hippocampus (Heinemann et al., 1992; Lothman et al., 1992; Goldberg and Coulter, 2013). Although hippocampus has multiple interacting nested loops, if the DG is the last to reach "critical mass," a synchronous discharge there could be responsible for the all-or-none expression of the oPD. It this is true, the oPDT, in its current configuration, is a sensitive measure of the strength of the "dentate gate" and could be useful for evaluating therapeutic interventions in this area (Krook-Magnuson et al., 2013, 2015). Non-synaptic propagation, often neglected in earlier studies of seizure, is also likely to play a role in generating the synchronous discharge in the closely situated structures of the hippocampus (Zhang et al., 2014).

Despite the widespread synchronous nature of the discharge, it is transient, and the system is surprisingly resilient to its effects on short time scales. By analyzing the oPD probabilities from one stimulus to the next, we found that the response is functionally independent of the previous stimulus in just a few seconds. Furthermore, closely spaced oPDs (1-s ISI) are suppressive to the system, significantly reducing the probability of another OPD in response to the subsequent stimulus. The suppressive effect of the oPD is likely due to a combination of ChR2 desensitization and the slow after-hyperpolarization (I $\mathrm{I}_{\mathrm{SAHP}}$; Alger and Nicoll, 1980; Lancaster and Adams, 1986). The fact that unitary PDs are suppressive and multiple repeated oPDs are required to initiate seizure suggests that either there is a reduction in the suppressive effect with each oPD, or that multiple PDs produce sufficient excitation to overcome the suppressive effects. In the context of spontaneous seizure, this makes it clear that seizures are a result of a slow transition to abnormal brain states, such as those presumably induced by persistence repetitive synchronous discharges in our model, which are permissive to self-sustaining seizure activity and that they are not simply the result of transient synchronous activity alone (Chang et al., 2018b).

The oPDT procedure allows for multiple threshold measurements over time; an important advantage over previous methods. For comparison, the recovery time for the 6-hz psychomotor seizure and minimal electroshock threshold is at least 4.4 and $7.5 \mathrm{~min}$, respectively (Brown et al., 1953). The enhanced temporal resolution of the oPDT can be used to estimate the functional pharmacokinetics of anti-epileptic drugs or to study the natural fluctuations in excitability that depend on brain state and behavior (Baud et al., 2018, 2019). The temporal resolution of the oPDT is limited by the number of stimuli used to generate the curve and the ISI. As we have demonstrated, stimuli are functionally independent when presented with $|S|>2$ s. Further reductions could be achieved by using a reduced subset of stimuli, optimized for baseline curves in each animal. For small changes, sampling at the 150 alone should be sufficient. When implemented in a closed-loop system, optimization techniques could be used to further reduce the number of stimuli necessary (MacKay, 1992).

On longer time scales (days to weeks), repeated stimulation of the brain is expected to produce a number of changes, some of which involve changes in plasticity and homeostatic regulation of the stimulated cells (Thiels et al., 1994; Oliet et al., 1997; Massey and Bashir, 2007). Recently, it was demonstrated that long-term (24 h) optogenetic stimulation of CA1 produces changes in spine density and synaptic plasticity (Moulin et al., 2019). Although we have demonstrated that the oPDT is stable over time, appropriate control experiments should be used and care should be taken when interpreting results to account for potential changes in the brain as a result of stimulation. 
The current study is focused on using optogenetic intensity-response curves to quantify excitability in the context of seizure activity, but the same procedure could be applied to any study that uses optogenetic stimulation as the independent variable with a stochastic dependent variable. Similar procedures could be performed with any appropriate optogenetically-induced cellular, molecular, physiologic, or behavioral output metric (Tischer and Weiner, 2014; Allen et al., 2015; Bugaj et al., 2016). Abnormal excitability is also associated with a number of other neurologic disorders including depression, autism, Alzheimer's, anxiety, drug addiction (and withdrawal), and schizophrenia (Santos et al., 2010; Friedman et al., 2014; Kourrich et al., 2015; Rau et al., 2015; Crabtree et al., 2017; Takarae and Sweeney, 2017). Correlating changes in excitability with behavior or neurochemical state in the context of these disorders may provide novel insights into the mechanisms of the underlying disease.

In summary, we show that synchronous optogenetic activation is sufficient to induce epileptiform PDs, and the systematic modulation of light intensity allows for precise estimation of the threshold between normal and abnormal activity. This approach provides a novel platform for testing the effects of therapeutic interventions on network excitability.

\section{References}

Alfonsa $\mathrm{H}$, Merricks EM, Codadu NK, Cunningham MO, Deisseroth K, Racca C, Trevelyan AJ (2015) The contribution of raised intraneuronal chloride to epileptic network activity. J Neurosci 35: $7715-7726$.

Alger BE, Nicoll RA (1980) Epileptiform burst afterhyperolarization: calcium-dependent potassium potential in hippocampal CA1 pyramidal cells. Science 210:1122-1124.

Allen BD, Singer AC, Boyden ES (2015) Principles of designing interpretable optogenetic behavior experiments. Learn Mem 22: 232-238.

Altar CA, Laeng P, Jurata LW, Brockman JA, Lemire A, Bullard J, Bukhman YV, Young TA, Charles V, Palfreyman MG (2004) Electroconvulsive seizures regulate gene expression of distinct neurotrophic signaling pathways. J Neurosci 24:2667-2677.

Aravanis AM, Wang LP, Zhang F, Meltzer LA, Mogri MZ, Schneider MB, Deisseroth K (2007) An optical neural interface: in vivo control of rodent motor cortex with integrated fiberoptic and optogenetic technology. J Neural Eng 4:S143-S156.

Arenkiel BR, Peca J, Davison IG, Feliciano C, Deisseroth K, Augustine GJ, Ehlers MD, Feng G (2007) In vivo light-induced activation of neural circuitry in transgenic mice expressing channelrhodopsin-2. Neuron 54:205-218.

Avoli M, D'Antuono M, Louvel J, Köhling R, Biagini G, Pumain R, D'Arcangelo G, Tancredi V (2002) Network and pharmacological mechanisms leading to epileptiform synchronization in the limbic system in vitro. Prog Neurobiol 68:167-207.

Barton ME, Klein BD, Wolf HH, White HS (2001) Pharmacological characterization of the $6 \mathrm{~Hz}$ psychomotor seizure model of partial epilepsy. Epilepsy Res 47:217-227.

Baud MO, Kleen JK, Mirro EA, Andrechak JC, King-Stephens D, Chang EF, Rao VR (2018) Multi-day rhythms modulate seizure risk in epilepsy. Nat Commun 9:88.

Baud MO, Ghestem A, Benoliel J-J, Becker C, Bernard C (2019) Endogenous multidien rhythm of epilepsy in rats. Exp Neurol 315:82-87.

Bragin A, Csicsvári J, Penttonen M, Buzsáki G (1997) Epileptic afterdischarge in the hippocampal-entorhinal system: current source density and unit studies. Neuroscience 76:1187-1203.
Bragin A, Engel J Jr, Wilson CL, Fried I, Mathern GW (1999) Hippocampal and entorhinal cortex high-frequency oscillations (100$500 \mathrm{~Hz}$ ) in human epileptic brain and in kainic acid-treated rats with chronic seizures. Epilepsia 40:127-137.

Bragin A, Wilson CL, Engel J Jr (2002) Increased afterdischarge threshold during kindling in epileptic rats. Exp Brain Res 144:3037.

Bragin A, Wilson CL, Almajano J, Mody I, Engel J Jr (2004) Highfrequency oscillations after status epilepticus: epileptogenesis and seizure genesis. Epilepsia 45:1017-1023.

Bragin A, Azizyan A, Almajano J, Wilson CL, Engel J Jr (2005) Analysis of chronic seizure onsets after intrahippocampal kainic acid injection in freely moving rats. Epilepsia 46:1592-1598.

Brown WC, Schiffman DO, Swinyard EA, Goodman LS (1953) Comparative assay of antiepileptic drugs by "psychomotor" seizure test and minimal electroshock threshold test. J Pharmacol Exp Ther 107:273-283.

Buchin A, Chizhov A, Huberfeld G, Miles R, Gutkin BS (2016) Reduced efficacy of the KCC2 cotransporter promotes epileptic oscillations in a subiculum network model. J Neurosci 36:1161911633.

Bugaj LJ, O’Donoghue GP, Lim WA (2016) Interrogating cellular perception and decision making with optogenetic tools. J Cell Biol 16:25-28.

Buzsáki G (1984) Feed-forward inhibition in the hippocampal formation. Prog Neurobiol 22:131-153.

Buzsáki G, Anastassiou CA, Koch C (2012) The origin of extracellular fields and currents - EEG, ECoG, LFP and spikes. Nat Rev Neurosci 13:407.

Cardin JA, Carlén M, Meletis K, Knoblich U, Zhang F, Deisseroth K, Tsai L-H, Moore Cl (2010) Targeted optogenetic stimulation and recording of neurons in vivo using cell-type-specific expression of channelrhodopsin-2. Nat Protoc 5:247-254.

Chang M, Dian JA, Dufour S, Wang L, Moradi Chameh H, Ramani M, Zhang L, Carlen PL, Womelsdorf T, Valiante TA (2018a) Brief activation of GABAergic interneurons initiates the transition to ictal events through post-inhibitory rebound excitation. Neurobiol. Dis 109:102-116.

Chang WC, Kudlacek J, Hlinka J, Chvojka J, Hadrava M, Kumpost V, Powell AD, Janca R, Maturana MI, Karoly PJ, Freestone DR, Cook MJ, Palus M, Otahal J, Jefferys JGR, Jiruska P (2018b) Loss of neuronal network resilience precedes seizures and determines the ictogenic nature of interictal synaptic perturbations. Nat Neurosci 21:1742-1752.

Cobb SR, Buhl EH, Halasy K, Paulsen O, Somogyi P (1995) Synchronization of neuronal activity in hippocampus by individual GABAergic interneurons. Nature 378:75.

Cossart R, Bernard C, Ben-Ari Y (2005) Multiple facets of GABAergic neurons and synapses: multiple fates of GABA signalling in epilepsies. Trends Neurosci 28:108-115.

Crabtree GW, Sun Z, Kvajo M, Broek JAC, Fénelon K, McKellar H, Xiao L, Xu B, Bahn S, O’Donnell JM, Gogos JA (2017) Alteration of neuronal excitability and short-term synaptic plasticity in the prefrontal cortex of a mouse model of mental illness. J Neurosci $37: 4158-4180$.

de Curtis M, Uva L, Gnatkovsky V, Librizzi L (2018) Potassium dynamics and seizures: why is potassium ictogenic? Epilepsy Res 143:50-59.

D'Agostino RB, Belanger A, D’Agostino RB Jr (1990) A suggestion for using powerful and informative tests of normality. Am Stat 44:316321.

Devinsky O, Vezzani A, Najjar S, Lanerolle NCD, Rogawski MA (2013) Glia and epilepsy: excitability and inflammation. Trends Neurosci 36:174-184.

Dobbins DL, Klorig DC, Smith T, Godwin DW (2018) Expression of channelrhodopsin-2 localized within the deep CA1 hippocampal sublayer in the Thy 1 line 18 mouse. Brain Res 1679:179-184.

Ellender TJ, Raimondo JV, Irkle A, Lamsa KP, Akerman CJ (2014) Excitatory effects of parvalbumin-expressing interneurons main- 
tain hippocampal epileptiform activity via synchronous afterdischarges. J Neurosci 34:15208-15222.

Enatsu R, Piao Z, O'Connor T, Horning K, Mosher J, Burgess R, Bingaman W, Nair D (2012) Cortical excitability varies upon ictal onset patterns in neocortical epilepsy: a cortico-cortical evoked potential study. Clin Neurophysiol 123:252-260.

Freestone DR, Kuhlmann L, Grayden DB, Burkitt AN, Lai A, Nelson TS, Vogrin S, Murphy M, D'Souza W, Badawy R, Nesic D, Cook MJ (2011) Electrical probing of cortical excitability in patients with epilepsy. Epilepsy Behav 22:S110-S118.

Friedman AK, Walsh JJ, Juarez B, Ku SM, Chaudhury D, Wang J, Li X, Dietz DM, Pan N, Vialou VF, Neve RL, Yue Z, Han MH (2014) Enhancing depression mechanisms in midbrain dopamine neurons achieves homeostatic resilience. Science 344:313-319.

Goddard GV, Mclntyre DC, Leech CK (1969) A permanent change in brain function resulting from daily electrical stimulation. Exp Neurol 25:295-330.

Goldberg EM, Coulter DA (2013) Mechanisms of epileptogenesis: a convergence on neural circuit dysfunction. Nat Rev Neurosci 14: 337-349.

Graef JD, Godwin DW (2010) Intrinsic plasticity in acquired epilepsy: too much of a good thing? Neuroscientist 16:487-495.

Hales CG, Pockett S (2014) The relationship between local field potentials (LFPs) and the electromagnetic fields that give rise to them. Front Syst Neurosci 8:233.

Heinemann U, Beck H, Dreier JP, Ficker E, Stabel J, Zhang CL (1992) The dentate gyrus as a regulated gate for the propagation of epileptiform activity. Epilepsy Res Suppl 7:273-280.

Herreras O (2016) Local field potentials: myths and misunderstandings. Front Neural Circuits 10:101.

Histed MH, Bonin V, Reid RC (2009) Direct activation of sparse, distributed populations of cortical neurons by electrical microstimulation. Neuron 63:508-522.

Hodgkin AL, Huxley AF (1952) A quantitative description of membrane current and its application to conduction and excitation in nerve. J Physiol 117:500-544.

Johnston D, Brown TH (1981) Giant synaptic potential hypothesis for epileptiform activity. Science 211:294-297.

Kairiss EW, Racine RJ, Smith GK (1984) The development of the interictal spike during kindling in the rat. Brain Res 322:101-110.

Karler R, Murphy V, Calder LD, Turkanis SA (1989) Pentylenetetrazol kindling in mice. Neuropharmacology 28:775-780.

Keller CJ, Huang Y, Herrero JL, Fini M, Du V, Lado FA, Honey CJ, Mehta AD (2018) Induction and quantification of excitability changes in human cortical networks. J Neurosci 38:5384-5398.

Khoshkhoo S, Vogt D, Sohal VS (2017) Dynamic, cell-type-specific roles for GABAergic interneurons in a mouse model of optogenetically inducible seizures. Neuron 93:291-298.

Klorig DC, Godwin DW (2014) A magnetic rotary optical fiber connector for optogenetic experiments in freely moving animals. $J$ Neurosci Methods 227:132-139.

Klorig DC, Masicampo M, Bass CE, Godwin DW (2014) Kindling, high frequency oscillations, and interictal spikes in an optogenetic model of seizure. Program No. 311.21. 2014 Neuroscience Meeting Planner. Washington, DC: Society for Neuroscience.

Klorig DC, Alberto G, Godwin DW (2017) Optogenetically induced population discharge threshold (OPDT) as a sensitive measure of excitability. Program No. 294.22. 2017 Neuroscience Meeting Planner. Washington, DC: Society for Neuroscience.

Kourrich S, Calu DJ, Bonci A (2015) Intrinsic plasticity: an emerging player in addiction. Nat Rev Neurosci 16:173-184.

Krook-Magnuson E, Armstrong C, Oijala M, Soltesz I (2013) Ondemand optogenetic control of spontaneous seizures in temporal lobe epilepsy. Nat Commun 4:1376.

Krook-Magnuson E, Armstrong C, Bui A, Lew S, Oijala M, Soltesz I (2015) In vivo evaluation of the dentate gate theory in epilepsy. J Physiol 593:2379-2388.

Lancaster B, Adams PR (1986) Calcium-dependent current generating the afterhyperpolarization of hippocampal neurons. J Neurophysiol 55:1268-1282.
Lin JY (2010) A user's guide to channelrhodopsin variants: features, limitations and future developments. Exp Physiol 96:19-25.

Lisman J, Cooper K, Sehgal M, Silva AJ (2018) Memory formation depends on both synapse-specific modifications of synaptic strength and cell-specific increases in excitability. Nat Neurosci 21:309-314.

Löscher W (2011) Critical review of current animal models of seizures and epilepsy used in the discovery and development of new antiepileptic drugs. Seizure 20:359-368.

Löscher W (2017) Animal models of seizures and epilepsy: past, present, and future role for the discovery of antiseizure drugs. Neurochem Res 42:1873-1888.

Löscher W, Reissmüller E, Ebert U (2000) Anticonvulsant efficacy of gabapentin and levetiracetam in phenytoin-resistant kindled rats. Epilepsy Res 40:63-77.

Lothman EW, Stringer JL, Bertram EH (1992) The dentate gyrus as a control point for seizures in the hippocampus and beyond. Epilepsy Res Suppl 7:301-313.

MacKay DJC (1992) Information-based objective functions for active data selection. Neural Comput 4:590-604.

Magloire V, Mercier MS, Kullmann DM, Pavlov I (2019) GABAergic interneurons in seizures: investigating causality with optogenetics. Neuroscientist 25:344-358.

Maru E, Goddard GV (1987) Alteration in dentate neuronal activities associated with perforant path kindling: I. Long-term potentiation of excitatory synaptic transmission. Exp Neurol 96:19-32.

Massey PV, Bashir ZI (2007) Long-term depression: multiple forms and implications for brain function. Trends Neurosci 30:176-184.

Matsumoto R, Kunieda T, Nair D (2017) Single pulse electrical stimulation to probe functional and pathological connectivity in epilepsy. Seizure 44:27-36.

Mclntyre DC, Kelly ME, Armstrong JN (1993) Kindling in the perirhinal cortex. Brain Res 615:1-6.

Meadows JP, Guzman-Karlsson MC, Phillips S, Brown JA, Strange SK, Sweatt JD, Hablitz JJ (2016) Dynamic DNA methylation regulates neuronal intrinsic membrane excitability. Sci Signal 9:ra83.

Miles R, Blaesse P, Huberfeld G, Wittner L, Kaila K (2012). Chloride homeostasis and GABA signaling in temporal lobe epilepsy. In: Jasper's basic mechanisms of the epilepsies (Noebels JL, Avoli M, Rogawski MA, Olsen RW, Delgado-Escueta AV, eds). Bethesda: National Center for Biotechnology Information.

Mizuseki K, Diba K, Pastalkova E, Buzsáki G (2011) Hippocampal CA1 pyramidal cells form functionally distinct sublayers. Nat Neurosci 14:1174-1181.

Moulin TC, Petiz LL, Rayêe D, Winne J, Maia RG, L. da Cruz RV Amaral OB, Leão RN (2019) Chronic in vivo optogenetic stimulation modulates neuronal excitability, spine morphology, and Hebbian plasticity in the mouse hippocampus. Hippocampus 29:755761.

Nicoll RA (2017) A brief history of long-term potentiation. Neuron 93:281-290.

Oliet SHR, Malenka RC, Nicoll RA (1997) Two distinct forms of long-term depression coexist in CA1 hippocampal pyramidal cells. Neuron 18:969-982.

Petersen $\mathrm{CCH}$ (2017) Whole-cell recording of neuronal membrane potential during behavior. Neuron 95:1266-1281.

Pinel JP, Rovner LI (1978) Electrode placement and kindling-induced experimental epilepsy. Exp Neurol 58:335-346.

Pinel JP, Skelton R, Mucha RF (1976) Kindling-related changes in afterdischarge "thresholds." Epilepsia 17:197-206.

Racine RJ (1972a) Modification of seizure activity by electrical stimulation: I. after-discharge threshold. Electroencephalogr Clin Neurophysiol 32:269-279.

Racine RJ (1972b) Modification of seizure activity by electrical stimulation: II. Motor seizure. Electroencephalogr Clin Neurophysiol 32:281-294.

Racine R, Okujava V, Chipashvili S (1972) Modification of seizure activity by electrical stimulation: III. Mechanisms. Electroencephalogr Clin Neurophysiol 32:295-299. 
Rau AR, Chappell AM, Butler TR, Ariwodola OJ, Weiner JL (2015) Increased basolateral amygdala pyramidal cell excitability may contribute to the anxiogenic phenotype induced by chronic earlylife stress. J Neurosci 35:9730-9740.

Rowley NM, White HS (2010) Comparative anticonvulsant efficacy in the corneal kindled mouse model of partial epilepsy: correlation with other seizure and epilepsy models. Epilepsy Res 92:163-169.

Santos SF, Pierrot N, Octave J-N (2010) Network excitability dysfunction in Alzheimer's disease: insights from in vitro and in vivo models. Rev Neurosci 21:153-171.

Sessolo M, Marcon I, Bovetti S, Losi G, Cammarota M, Ratto GM, Fellin T, Carmignoto G (2015) Parvalbumin-positive inhibitory interneurons oppose propagation but favor generation of focal epileptiform activity. J Neurosci 35:9544-9557.

Shivacharan RS, Chiang CC, Zhang M, Gonzalez-Reyes LE, Durand DM (2019) Self-propagating, non-synaptic epileptiform activity propagates by endogenous electric fields. Exp Neurol 317:119128.

Sloviter RS (1989) Calcium-binding protein (calbindin-D28k) and parvalbumin immunocytochemistry: localization in the rat hippocampus with specific reference to the selective vulnerability of hippocampal neurons to seizure activity. J Comp Neurol 280:183196.

Spiegel EA (1937) Quantitative determination of the convulsive reactivity by electric stimulation of the brain with the skull intact. J Lab Clin Med 22:1274-1276.

Staba RJ, Wilson CL, Bragin A, Fried I, Engel J (2002) Quantitative analysis of high-frequency oscillations $(80-500 \mathrm{~Hz})$ recorded in human epileptic hippocampus and entorhinal cortex. J Neurophysiol 88:1743-1752.

Sterling P, Laughlin S (2015) Principles of neural design. Cambridge: The MIT Press.

Stover KR, Lim S, Zhou T-L, Stafford PM, Chow J, Li H, Sivanenthiran N, Mylvaganam S, Wu C, Weaver DF, Eubanks J, Zhang L (2017) Susceptibility to hippocampal kindling seizures is increased in aging C57 black mice. IBRO Rep 3:33-44.

Swinyard EA, Brown WC, Goodman LS (1952) Comparative assays of antiepileptic drugs in mice and rats. J Pharmacol Exp Ther 106:319-330.

Takarae Y, Sweeney J (2017) Neural hyperexcitability in autism spectrum disorders. Brain Sci 7.

Thiels E, Barrionuevo G, Berger TW (1994) Excitatory stimulation during postsynaptic inhibition induces long-term depression in hippocampus in vivo. J Neurophysiol 72:3009-3016.

Ting JT, Feng G (2013) Development of transgenic animals for optogenetic manipulation of mammalian nervous system function: progress and prospects for behavioral neuroscience. Behav Brain Res 255:3-18.

Tischer D, Weiner OD (2014) Illuminating cell signalling with optogenetic tools. Nat Rev Mol Cell Biol 15:551-558.

Traub RD, Jefferys JG (1994) Simulations of epileptiform activity in the hippocampal CA3 region in vitro. Hippocampus 4:281-285.
Valero M, Cid E, Averkin RG, Aguilar J, Sanchez-Aguilera A, Viney TJ, Gomez-Dominguez D, Bellistri E, de la Prida LM (2015) Determinants of different deep and superficial CA1 pyramidal cell dynamics during sharp-wave ripples. Nat Neurosci 18:1281-1290.

Wahlstrom-Helgren S, Klyachko VA (2016) Dynamic balance of excitation and inhibition rapidly modulates spike probability and precision in feed-forward hippocampal circuits. J Neurophysiol 116:2564-2575.

Wang H, Peca J, Matsuzaki M, Matsuzaki K, Noguchi J, Qiu L, Wang D, Zhang F, Boyden E, Deisseroth K, Kasai H, Hall WC, Feng G, Augustine GJ (2007) High-speed mapping of synaptic connectivity using photostimulation in channelrhodopsin-2 transgenic mice. Proc Natl Acad Sci USA 104:8143-8148.

Wang Y, Xu C, Xu Z, Ji C, Liang J, Wang Y, Chen B, Wu X, Gao F, Wang S, Guo Y, Li X, Luo J, Duan S, Chen Z (2017) Depolarized GABAergic signaling in subicular microcircuits mediates generalized seizure in temporal lobe epilepsy. Neuron 95:92-105.e5.

Weitz AJ, Fang Z, Lee HJ, Fisher RS, Smith WC, Choy M, Liu J, Lin $\mathrm{P}$, Rosenberg M, Lee JH (2015) Optogenetic fMRI reveals distinct, frequency-dependent networks recruited by dorsal and intermediate hippocampus stimulations. Neuroimage 107:229-241.

Wendling F, Gerber U, Cosandier-Rimele D, Nica A, De Montigny J, Raineteau O, Kalitzin S, Lopes da Silva F, Benquet P (2016) Brain (hyper)excitability revealed by optimal electrical stimulation of GABAergic interneurons. Brain Stimulat 9:919-932.

Williams JC, Xu J, Lu Z, Klimas A, Chen X, Ambrosi CM, Cohen IS, Entcheva E (2013) Computational optogenetics: empiricallyderived voltage- and light-sensitive channelrhodopsin-2 model. PLoS Comput Biol 9:e1003220.

Yeckel MF, Berger TW (1990) Feedforward excitation of the hippocampus by afferents from the entorhinal cortex: redefinition of the role of the trisynaptic pathway. Proc Natl Acad Sci USA 87:5832-5836.

Yekhlef L, Breschi GL, Lagostena L, Russo G, Taverna S (2015) Selective activation of parvalbumin- or somatostatin-expressing interneurons triggers epileptic seizurelike activity in mouse medial entorhinal cortex. J Neurophysiol 113:1616-1630.

Yizhar O, Fenno LE, Davidson TJ, Mogri M, Deisseroth K (2011) Optogenetics in neural systems. Neuron 71:9-34.

Yonekawa WD, Kupferberg HJ, Woodbury DM (1980) Relationship between pentylenetetrazol-induced seizures and brain pentylenetetrazol levels in mice. J Pharmacol Exp Ther 214:589-593.

Zhang M, Ladas TP, Qiu C, Shivacharan RS, Gonzalez-Reyes LE, Durand DM (2014) Propagation of epileptiform activity can be independent of synaptic transmission, gap junctions, or diffusion and is consistent with electrical field transmission. J Neurosci 34:1409-1419.

Zijlmans M, Jiruska P, Zelmann R, Leijten FSS, Jefferys JGR, Gotman $J(2012)$ High-frequency oscillations as a new biomarker in epilepsy. Ann Neurol 71:169-178.

Ziskind E, Sjaardema H, Bercel NA (1946) Minimal electroencephalographic response to metrazol as a method for measuring the convulsive threshold for use in human beings. Science 104:462. 